Subscriber access provided by Caltech Library

\title{
Article
}

\section{Design, Synthesis, and Self-Assembly of Polymers with Tailored Graft Distributions}

Alice B. Chang, Tzu-Pin Lin, Niklas B. Thompson, Shao-Xiong Luo, Allegra

Lauren Liberman-Martin, Hsiang-Yun Chen, Byeongdu Lee, and Robert H. Grubbs

J. Am. Chem. Soc., Just Accepted Manuscript • DOI: 10.1021/jacs.7b10525 • Publication Date (Web): 08 Nov 2017

Downloaded from http://pubs.acs.org on November 9, 2017

\section{Just Accepted}

"Just Accepted" manuscripts have been peer-reviewed and accepted for publication. They are posted online prior to technical editing, formatting for publication and author proofing. The American Chemical Society provides "Just Accepted" as a free service to the research community to expedite the dissemination of scientific material as soon as possible after acceptance. "Just Accepted" manuscripts appear in full in PDF format accompanied by an HTML abstract. "Just Accepted" manuscripts have been fully peer reviewed, but should not be considered the official version of record. They are accessible to all readers and citable by the Digital Object Identifier (DOI®). "Just Accepted" is an optional service offered to authors. Therefore, the "Just Accepted" Web site may not include all articles that will be published in the journal. After a manuscript is technically edited and formatted, it will be removed from the "Just Accepted" Web site and published as an ASAP article. Note that technical editing may introduce minor changes to the manuscript text and/or graphics which could affect content, and all legal disclaimers and ethical guidelines that apply to the journal pertain. ACS cannot be held responsible for errors or consequences arising from the use of information contained in these "Just Accepted" manuscripts. 


\section{INTRODUCTION}

Molecular architecture impacts the chemical and physical properties of all polymers. Achieving precise control over the chain connectivity, sequence, and symmetry presents synthetic challenges as well as rich opportunities for materials design. Over the past several decades, advances in controlled polymerization have enabled the synthesis of polymers with complex architectures..$^{1-4}$ Graft polymers are a class of such nonlinear architectures featuring polymeric side chains attached to a polymeric backbone. The grafting density and distribution of grafts along the backbone determine the steric interactions between side chains and in turn influence the physical properties. Graft polymers display many unique properties compared to their linear analogues, such as extended chain conformations, ${ }^{5-8}$ increased entanglement molecular weights, ${ }^{9-12}$ and architecturedependent rheological behavior. ${ }^{13-16}$ Recent studies have harnessed these properties in a wide variety of applications in photonics, ${ }^{17-19}$ drug delivery, ${ }^{20-22}$ transport, ${ }^{23-24}$ and thermoplastics. ${ }^{25-26}$ Continued progress in synthetic command over polymer architecture enables further studies of structure-property relationships and inspires new potential applications.

Graft polymers represent ideal platforms to study how chain connectivity defines nanostructures and thereby physical prop- erties. Despite the importance of grafting density and graft distribution, synthetic strategies that permit precise control of these parameters are currently limited. Grafting-to ${ }^{27-30}$ and grafting-from ${ }^{31-34}$ approaches require multiple steps in which side chains are either attached to or grown from a pre-formed backbone. Steric congestion along the backbone typically prevents precise control over the molecular weight, grafting density, and side chain distribution. As a result, the synthesis of well-defined architectural variants - let alone materials with variable chemical compositions - is challenging. Graftingthrough ring-opening metathesis polymerization (ROMP) closes this gap by affording wide functional group tolerance and enabling simultaneous control over side chain and backbone lengths. ${ }^{35-37}$ We recently introduced a ROMP strategy that provides access to polymers with uniform grafting densities spanning the linear to bottlebrush regimes. ${ }^{38}$ In this report, we further expand the scope of architectural design by demonstrating that ROMP can be exploited to further tune "molecular shapes."

Our approach employs controlled copolymerization of a macromonomer and a small-molecule diluent. The relative reactivity of the two co-monomers directly dictates the spatial arrangement of the side chains. For example, if the macromonomer and diluent copolymerize at approximately the same rate, the side chains are therefore uniformly distributed along the polymer backbone (Figure 1A). Such polymers are widely termed 
"cylindrical molecular brushes" due to their steric-induced stiffness and axes of symmetry. ${ }^{39-43}$ These cylindrical brushes can be modeled as wormlike chains with the same average crosssectional radius $\left(R_{\mathrm{c}}\right)$ along the entire backbone. ${ }^{5,44-46}$ On the other hand, if the macromonomer and diluent copolymerize at different rates, the resulting gradient sequences are anticipated to template different side chain conformations. Depending on the extent of side chain stretching, $R_{\mathrm{c}}$ varies and tapered, noncylindrical molecular shapes result (Figure 1B). Control over the co-monomer distribution therefore opens opportunities to manipulate the chain dimensions and physical properties.

In this report, we provide the first demonstration that varying the stereochemistry and steric profiles of discrete co-monomers enables the synthesis of well-defined graft polymers with tunable grafting density and graft distribution. We will first discuss the homopolymerization kinetics of a library of discrete norbornenyl monomers, then build complexity through controlled copolymerizations of these small molecules with $\omega$-norbornenyl macromonomers. Trends in the homo- and cross-propagation rates will be outlined to provide guidance for future rational design of polymer architectures with arbitrary graft chemistry and distribution. We will illustrate the versatility of this copolymerization strategy through the synthesis of graft polymers with different anticipated molecular shapes. The physical consequences of varying the graft distribution will be discussed in the context of block polymer self-assembly.

\section{RESULTS AND DISCUSSION}

Monomer Design. Previous work introduced endo, exo-norbornenyl dialkylesters as appropriate discrete monomers (diluents) to control the grafting density of polymers with poly(D,Llactide) (PLA, $M_{\mathrm{n}}=3230 \mathrm{~g} \mathrm{~mol}^{-1}$ ), polydimethylsiloxane $\left(\right.$ PDMS, $M_{\mathrm{n}}=1280 \mathrm{~g} \mathrm{~mol}^{-1}$ ), or polystyrene (PS, $M_{\mathrm{n}}=3990 \mathrm{~g}$ mol $^{-1}$ ) side chains. ${ }^{38}$ Across all macromonomer/diluent combinations and feed ratios, kinetic analyses indicated approximately equal rates of co-monomer consumption and therefore approximately uniform side chain distributions. Obtaining nonuniform side chain distributions requires changing the relative reactivity of the macromonomer and diluent. We propose that designing new small-molecule co-monomers is the most convenient route. This strategy avoids potentially tedious endgroup modifications to the macromonomers and retains the synthetic utility of one-pot batch copolymerization. While semibatch methods (involving continuous addition of one monomer to another) can afford wide control over polymer sequences, ${ }^{47-}$ 48 they require additional instrumentation and optimization of factors such as feed ratio and feed rate. ${ }^{49-50}$ Similarly, while sequential addition of macromonomers with different molecular weights can also provide access to tapered architectures, ${ }^{51}$ this approach requires the preparation of multiple well-defined macromonomers and fixes the grafting density at $100 \%$.

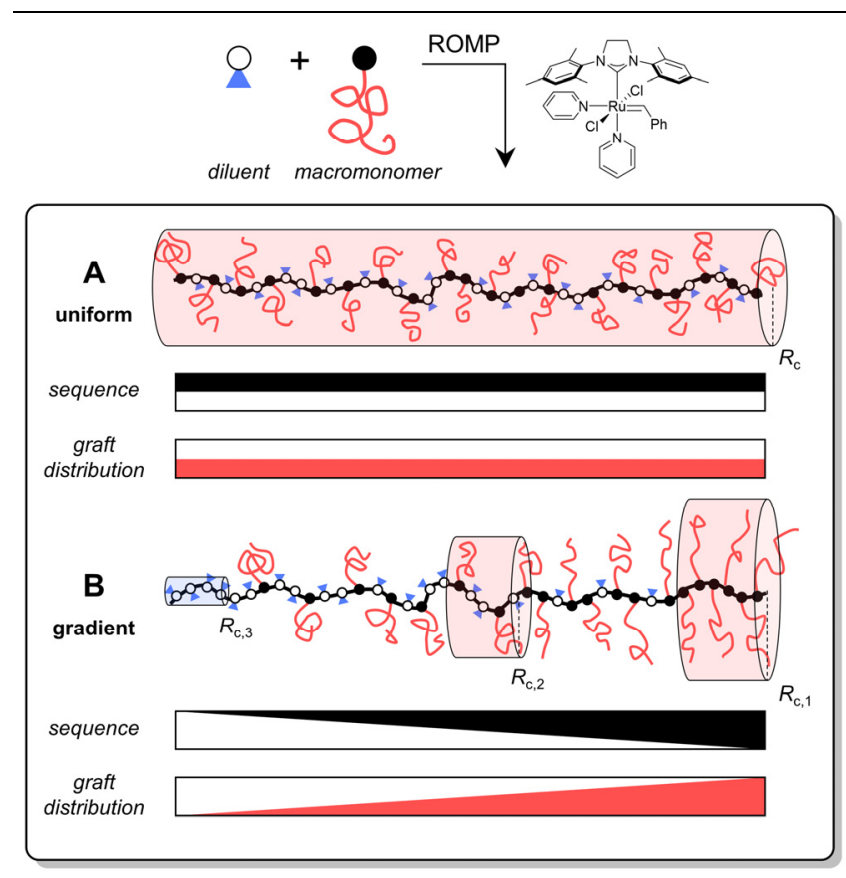

Figure 1. Grafting-through ROMP of a small-molecule diluent (white) and a macromonomer (black). Since the side chains (red) are connected to certain backbone units, control over the backbone sequence directly determines the side chain distribution: (A) uniform, (B) gradient, etc. The anticipated average cross-sectional radius of gyration $\left(R_{\mathrm{c}}\right)$ is indicated. For ease of visualization, chains are illustrated in the limit of fully extended backbones.

Chart 1 highlights opportunities for monomer design. The polymerizable strained olefin, anchor group, and substituents can all be readily modified. Substituted norbornenes were selected for our study due to (1) the ease of modifying the stereochemistry and functional groups and (2) the high ring strain, which disfavors unproductive [2+2] cycloreversion. ${ }^{52}$ The importance of the anchor group in homopolymerization kinetics has been demonstrated for both discrete norbornenes ${ }^{53-54}$ and more recently, $\omega$-norbornenyl macromonomers. ${ }^{55}$ In contrast, anchor group effects on the copolymerization of discrete monomers and macromonomers have not been studied. In order to investigate these effects, discrete substituted norbornenes with five different types of anchor groups were synthesized: endo,exo-diester ( $d x$-DE, 1), endo,endo-diester ( $d d$-DE, 2), exo,exo-diester $(x x$-DE, 3), endo-imide $(d-\mathrm{I}, 4)$, and exo-imide $(x-\mathrm{I}, 5)$. For each anchor group, monomers with different substituents (R) were prepared, including for example homologous alkyl groups or para-substituted phenyl rings. All monomers can be prepared in high yields in one or two steps from commercially available starting materials. (Further synthetic details can be found in the Supporting Information.) These steric and electronic variations provide a diverse library of co-monomers for ROMP.

The homopolymerization kinetics of all monomers were studied under the same conditions. ROMP of each monomer in dichloromethane $([\mathrm{M}]=50 \mathrm{mM})$ was catalyzed by the fast-initiating third-generation ruthenium metathesis catalyst, $\left(\mathrm{H}_{2} \mathrm{IMes}\right)(\mathrm{pyr})_{2}(\mathrm{Cl})_{2} \mathrm{Ru}=\mathrm{CHPh}\left([\mathbf{G 3}]_{0}=0.5 \mathrm{mM}\right)$. Over the course of the polymerization, aliquots $(<20 \mu \mathrm{L})$ were collected and immediately quenched into separate vials containing excess 
ethyl vinyl ether and a silica-bound metal scavenger (SiliaMetS). ${ }^{56}$ Removing the quenched ruthenium complex from solution prevents potential reactivation and undesired metathesis that would affect the apparent rates. Analysis by size-exclusion chromatography (SEC) and ${ }^{1} \mathrm{H}$ NMR spectroscopy indicates first-order rate dependence on monomer concentration. The first- and second-order rate constants $\left(k_{\mathrm{obs}}\right.$ and $k_{\text {homo, }}$, respectively) were determined according to Eq. 1:

$$
-\frac{\mathrm{d}[\mathrm{M}]_{t}}{\mathrm{dt}}=k_{\mathrm{obs}}[\mathrm{M}]_{t}=k_{\mathrm{homo}}[\mathbf{G} 3]_{0}[\mathrm{M}]_{t}
$$

For many monomers, the rate constants were determined at least in triplicate. The calculated values typically varied by no more than five percent (Figure S6).

\section{Chart 1. Monomer design for ring-opening metathesis copolymerization.}

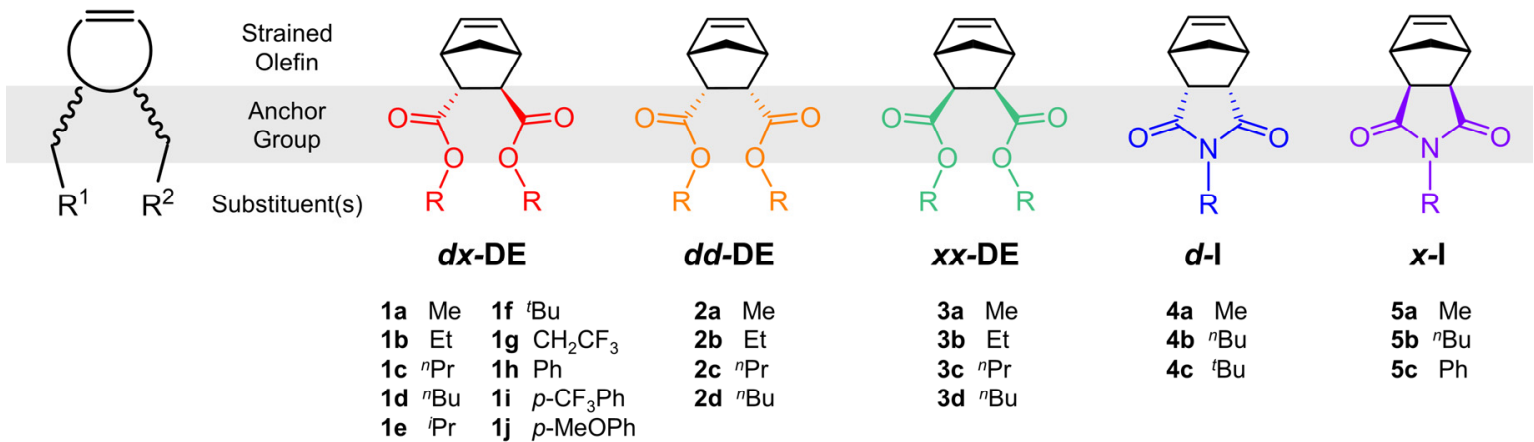

Studying trends in $k_{\text {homo }}$ with variations in steric and electronic structure guides monomer design. The first class of monomers studied herein features endo,exo-diester anchor groups $(d x$-DE). The homopolymerization kinetics of ten $d x$-DE monomers with different substituents were analyzed $(\mathbf{1 a}-\mathbf{1 j}$, Figure 2). The monomers were readily synthesized by esterification of commercially available norbornene endo,exo-dicarboxylic acid with the appropriate alcohol (1a-d, Scheme S1). (For the synthesis of $\mathbf{1 e}-\mathbf{1 j}$, the acyl chloride derivatives were required, Scheme S2.) In a series of monomers with homologous alkyl substituents ( $\mathrm{R}=$ methyl, ethyl, $n$-propyl, $n$-butyl; 1a-d), $k_{\text {homo }}$ decreases with increasing substituent size. Increasing the steric bulk with isopropyl- and tert-butyl-substituted monomers (1ef) further decreases $k_{\text {homo. }}$. These results indicate that sterics clearly impact the homopolymerization kinetics: for example, the methyl-substituted monomer polymerizes over three times faster than the tert-butyl-substituted analogue $\left(k_{\text {homo }}=18.7\right.$ versus $\left.5.36 \mathrm{M}^{-1} \mathrm{~s}^{-1}\right)$. The effects of electronic variations were also studied. Monomers with ethyl $\left(\mathbf{1 b}, 14.6 \mathrm{M}^{-1} \mathrm{~s}^{-1}\right)$ and trifluoroethyl $\left(\mathbf{1 g}, 10.5 \mathrm{M}^{-1} \mathrm{~s}^{-1}\right)$ substituents polymerize at approximately the same rate. Comparison of $d x$-DE monomers with different para-substituted phenyl rings further reveals that the electronic effects are minor. $d x$-norbornenyl diphenylester (1h) has a larger $k_{\text {homo }}\left(8.36 \mathrm{M}^{-1} \mathrm{~s}^{-1}\right)$ than monomers with either an electron-withdrawing para-trifluoromethyl group $\left(\mathbf{1 i}, 5.14 \mathrm{M}^{-1}\right.$ $\left.\mathrm{s}^{-1}\right)$ or an electron-donating para-methoxy group $\left(\mathbf{1 j}, 7.76 \mathrm{M}^{-1}\right.$ $\mathrm{s}^{-1}$ ). These electronic variations may exist too far away from the polymerizable olefin to affect $k_{\text {homo. }}$. Modifying norbornene itself rather than the distal substituents (for example, by substituting oxanorbornene or otherwise changing the bridge position) may result in more apparent electronic effects.

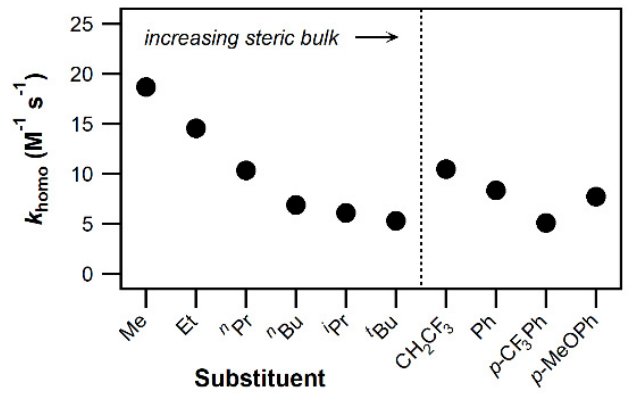

Figure 2. Homopolymerization rate constants ( $\left.k_{\text {homo }}\right)$ for substituted endo,exo-norbornenyl diester monomers (left to right: $\mathbf{1 a}-\mathbf{j}$ ). khomo decreases with increasing steric bulk $\left(\mathrm{R}=\mathrm{Me}\right.$ to $\left.{ }^{t} \mathrm{Bu}, \mathbf{1} \mathbf{a}-\mathbf{f}\right)$. $k$ homo does not change significantly with electronic changes via fluorination (1g) or para-substitution of a phenyl ring $(\mathbf{1 h}-\mathbf{j})$.

Changing the stereochemistry of the diester anchor groups further demonstrates the effects of steric variations on polymerization rates. (Synthetic details: Schemes S3-S4.) Comparing series with the same substituents (Figure 3A) indicates that $d x$ DE monomers (1a-d) all polymerize significantly faster than the corresponding endo,endo isomers $(d d-\mathrm{DE}, \mathbf{2 a - d})$ and slightly slower than the corresponding exo,exo isomers $(x x-\mathrm{DE}$, 3a-d). For example, the measured $k_{\text {homo }}$ for $d x$-norbornenyl dimethylester is $18.7 \mathrm{M}^{-1} \mathrm{~s}^{-1}$, while $k_{\text {homo }}$ values for the $d d-\mathrm{DE}$ and $x x$-DE analogues are $2.24 \mathrm{M}^{-1} \mathrm{~s}^{-1}$ and $30.8 \mathrm{M}^{-1} \mathrm{~s}^{-1}$, respectively. The same anchor group trend occurs for ethyl-, $n$-propyl-, and $n$-butyl-substituted norbornenyl diesters and is anticipated to be independent of the substituent.

In order to further examine the relationship between anchor groups and homopolymerization kinetics, norbornenyl monomers with endo-imide $(d-\mathrm{I})$ and exo-imide $(x-\mathrm{I})$ linkages were also synthesized (Schemes S5-S6). The $x$-I anchor group has been widely incorporated in macromonomers toward the synthesis of bottlebrush polymers by grafting-through ROMP, ${ }^{21,55,57-59}$ motivating our interest in imide-based diluents. Compared to diester anchor groups, imides are more rigid due 
to their fused rings and thereby change the monomer steric profile. The electronic character differs as well, since the electron density of an imide oxygen is typically greater than the electron density of an ester oxygen. The interplay of steric and electronic influences will be discussed further in the following section.

Figure 3B compares $k_{\text {homo }}$ for monomers with each of the five anchor groups. The endo/exo rate difference between $d$-I and $x$-I is magnified compared to the endo/exo rate differences observed among the diester-substituted monomers. The $k_{\text {homo }}$ values for methyl-substituted $d d$-DE and $x x$ - DE are 2.24 and $30.8 \mathrm{M}^{-1} \mathrm{~s}^{-1}$ respectively, representing a tenfold rate difference; in comparison, the $k_{\text {homo }}$ values for methyl-substituted $d$-I and $x$ I are 0.814 and $82.4 \mathrm{M}^{-1} \mathrm{~s}^{-1}$ respectively, representing a hundredfold rate difference. Figure $3 \mathrm{~B}$ also shows that the steric effects of the R group are smaller for $x$-I and $d$-I compared to the diester series. For monomers containing the same substituents, the following trend in $k_{\text {homo }}$ is observed: $d$ - $\mathrm{I}<d d-\mathrm{DE}<d x$ $\mathrm{DE}<x x$-DE $<x$-I.

Figure 4 and Table S1 summarize the homopolymerization kinetics for all monomers studied herein. Variations in the anchor groups and substituents afford a wide range of $k_{\text {homo }}$ over two orders of magnitude, spanning $0.362 \mathrm{M}^{-1} \mathrm{~s}^{-1}$ (2d) to 82.4 $\mathrm{M}^{-1} \mathrm{~s}^{-1}(\mathbf{5 a})$. This library of monomers can be readily diversified by simple esterification reactions, providing a versatile platform for tuning the polymerization rates. Understanding the origin of trends in $k_{\text {homo }}$ provides insight into the ROMP mechanism. While developing a complete mechanistic understanding is outside the scope of this study, we aim to identify key components of $k$ homo in order to facilitate applications of this method as well as future monomer design.
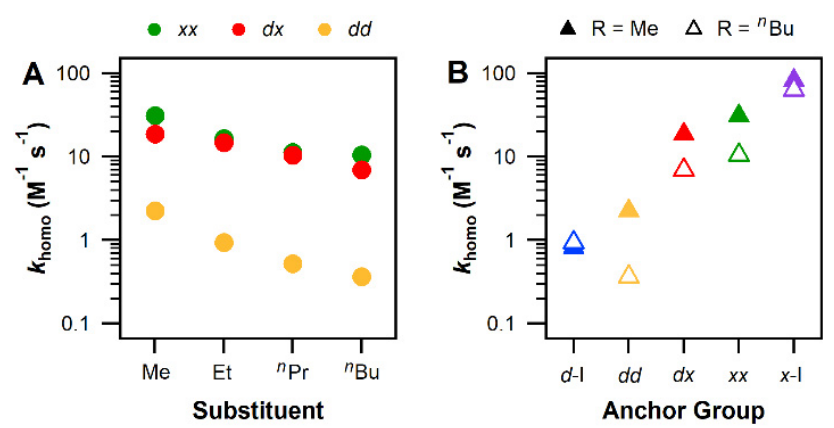

Figure 3. (A) Homopolymerization rate constants $\left(k_{\text {homo }}\right)$ for monomers with exo,exo-diester ( $x x$, green), endo,exo-diester ( $d x$, red), and endo,endo-diester ( $d d$, yellow) anchor groups. Comparison of $k_{\text {homo }}$ for monomers with $\mathrm{R}=\mathrm{Me}$, Et, ${ }^{n} \mathrm{Pr}$, and ${ }^{n} \mathrm{Bu}$ supports the steric influences of stereochemistry and substituent size. (B) $k_{\text {homo }}$ for Me- and ${ }^{n} \mathrm{Bu}$-substituted monomers with each of the five anchor groups; endo-imide ( $d$-I, blue) and exo-imide ( $x$-I, purple).

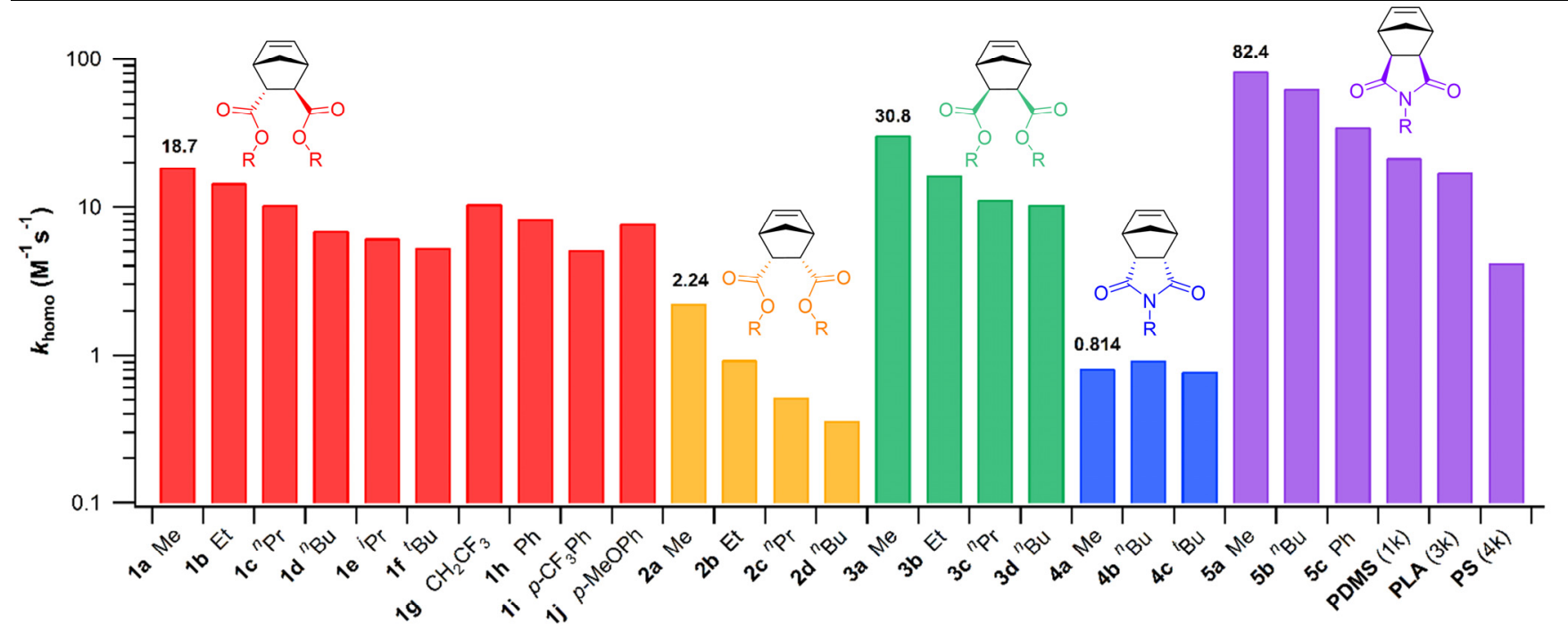

Figure 4. Plot of $k$ homo values for all monomers studied herein. The monomers are sorted according to their anchor groups: left to right: endo, exo-diester (red, 1a-j), endo, endo-diester (yellow, 2a-d), exo, exo-diester (green, 3a-d), endo-imide (blue, $\mathbf{4 a - c}$ ), and exo-imide (purple, $\mathbf{5 a - c}$ and macromonomers). $k$ homo values for methyl-substituted monomers are provided for comparison.

Origin of Rate Trends. Polymerization rates are determined by a combination of steric and electronic factors. Our results suggest that steric effects dominate: (1) In a series of monomers with homologous alkyl R groups, the electronic character is similar but $k_{\text {homo }}$ decreases as the steric bulk increases (Figure 2). (2) $k_{\text {homo }}$ is relatively insensitive to distal electronic variations (for example, via para-substitution of phenyl R groups, Figure 2). (3) $k_{\text {homo }}$ decreases for endo-substituted monomers compared to the corresponding exo isomers (Figure 3). In agreement with this work, previous studies of the ROMP of norbornene derivatives have also observed that endo isomers polymerize more slowly than their exo counterparts. ${ }^{54,60-63}$
The observed rate trends could be motivated by a combination of factors, including but not limited to pyridine coordination, olefin coordination, cycloaddition, and formation of a sixmembered chelate involving the ruthenium center and the esteror imide-functionalized chain end. ${ }^{64}$ In order to deconvolute these potential contributions to $k_{\text {homo, }}$ we examined the mechanism of ROMP. Based on previously reported results for related phosphine-based catalysts, ${ }^{65-67}$ we proposed a dissociative pathway (Figure $5 \mathrm{~A})$ in which pyridine dissociation $\left(K_{\mathrm{eq}, 1}=k_{1} / k_{-1}\right.$, $\left.K_{\text {eq, } 2}=k_{2} / k_{-2}\right)$ generates a 14 -electron intermediate (b) that can coordinate with a free olefin (c, $\left.K_{\text {eq, } 3}=k_{3} / k_{-3}\right)$. The olefin adduct then undergoes cycloaddition $\left(k_{4}\right)$ to form a metallacyclobutane 
intermediate. Subsequent cycloreversion yields a $\mathrm{P}_{\mathrm{n}+1}$ alkylidene and regenerates the 14-electron species. From a Van't Hoff analysis, Guironnet and coworkers recently reported an equilibrium constant $K_{\text {eq, } 1}=k_{1} / k_{-1}=0.5 \mathrm{M}$ in $\mathrm{CD}_{2} \mathrm{Cl}_{2}$ at $298 \mathrm{~K}^{68}$ In agreement with this work, we observed a similar $K_{\text {eq, } 1}$ value from ${ }^{1} \mathrm{H}$ NMR pyridine titration experiments $(0.25 \mathrm{M}$, Figure S7). The large $K_{\text {eq, } 1}$ value indicates that $>99.8 \%$ of the precatalyst $\mathbf{G} 3$ exists as the monopyridine adduct in solution under the conditions employed in our homo- and copolymerization studies $\left([\mathbf{G} 3]_{0}=0.5 \mathrm{mM}\right)$. As a result, the concentration of free pyridine is approximately equal to the initial concentration of $\mathbf{G 3}$ (i.e., $[\mathrm{pyr}] \approx[\mathbf{G} 3]_{0}$ ). We derived a simplified rate expression corresponding to a proposed dissociative ROMP pathway in which olefin coordination is the rate-limiting step: ${ }^{69}$

$$
-\frac{\mathrm{d}[\mathrm{M}]_{t}}{\mathrm{dt}}=k_{\mathrm{homo}}[\mathbf{G 3}]_{0}[\mathrm{M}]_{t} \approx \frac{K_{\mathrm{eq}, 2} k_{3}}{K_{\mathrm{eq}, 2}+[\mathrm{pyr}]}[\mathbf{G 3}]_{0}[\mathrm{M}]_{t}
$$

In this rate expression, $K_{\mathrm{eq}, 2}$ corresponds to dissociation of the second pyridine and is affected by the identity of the alkylidene ligand. At high catalyst concentrations ([pyr] $>>K_{\mathrm{eq}, 2}$ ), a pseudo-zeroth-order dependence on $[\mathbf{G} 3]_{0}$ is observed. ${ }^{68}$ At low catalyst concentrations however, we observed a rate dependence on $[\mathbf{G 3}]_{0}$ for monomers 5a and 5b (Figure S8). Collectively, these kinetic analyses are consistent with a dissociative pathway. ${ }^{70}$

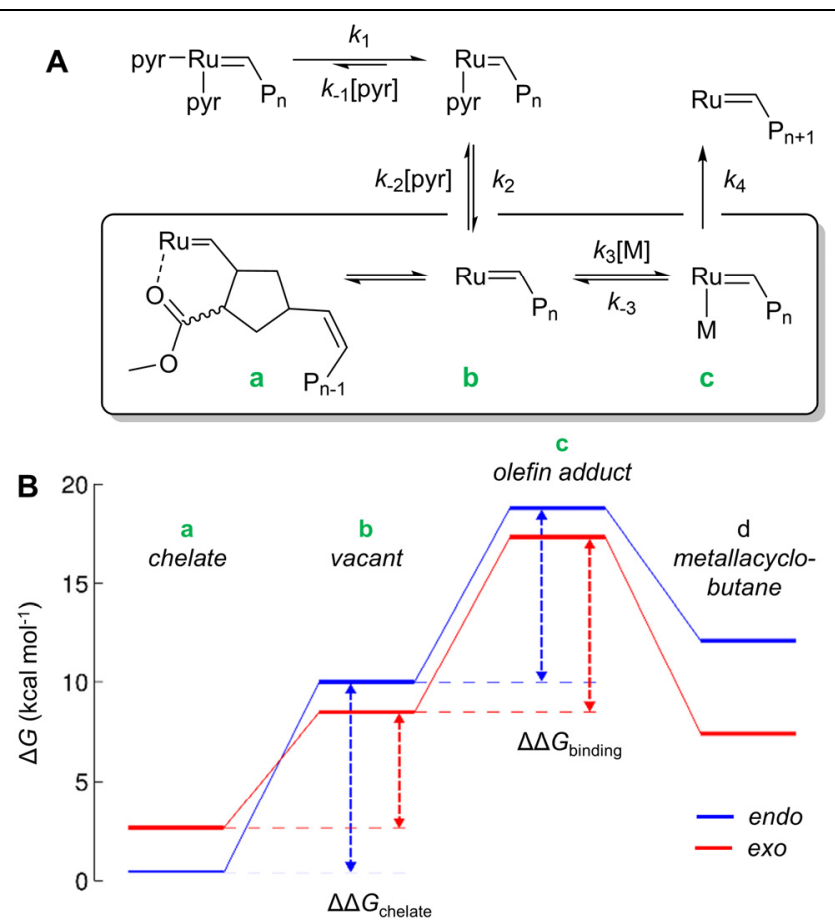

Figure 5. (A) Proposed dissociative ROMP pathway for G3. (B) DFT-calculated free energy diagram corresponding to one ROMP cycle for endo- (2a, blue) and exo-substituted (3a, red) norbornenyl monomers. The following intermediates were calculated: (a) sixmembered $\mathrm{Ru}-\mathrm{O}$ chelate, (b) 14-electron vacant species, (c) olefin adduct, and (d) metallacyclobutane.

Density functional theory (DFT) methods were employed to address potential chelation effects. Chelation sequesters the catalyst in an unproductive form (Figure 5A, a) and therefore slows the polymerization rate. ${ }^{71}$ For methyl-substituted endo,endoand exo,exo-norbornenyl diesters (2a and $\mathbf{3 a}$, respectively), the ground-state potential energy surfaces corresponding to one productive ROMP cycle were computed (Figures 5B and S9). The relative free energies at $298 \mathrm{~K}(\Delta G)$ indicate that formation of the six-membered chelate is more favorable for the endo isomer $\left(\Delta \Delta G_{\text {chelate }}=9.64 \mathrm{kcal} \mathrm{mol}^{-1}\right)$ than for the exo isomer $(\Delta \Delta G$ chelate $\left.=5.87 \mathrm{kcal} \mathrm{mol}^{-1}\right)$. The calculated free energies corresponding to olefin coordination to the vacant species, $\Delta \Delta G_{\text {bind- }}$ ing, are similar for the endo and exo isomers $(8.86$ and $8.91 \mathrm{kcal}$ $\mathrm{mol}^{-1}$, respectively). These results indicate that disruption of chelation by olefin binding should be more favorable for exo isomers than endo isomers (by $3.72 \mathrm{kcal} \mathrm{mol}^{-1}$ ). This disparity provides a plausible motive for the observed endo/exo rate differences $\left(k_{\text {homo }}=30.8 \mathrm{M}^{-1} \mathrm{~s}^{-1}\right.$ for $\mathbf{3 a}, 2.24 \mathrm{M}^{-1} \mathrm{~s}^{-1}$ for $\mathbf{2 a}$ ). These results are consistent with previous reports on the ROMP of discrete norbornenyl monomers with similar ruthenium catalysts ${ }^{64,66,72}$ and are anticipated to be valid whether olefin coordination $\left(k_{3}<<k_{4}\right)$ or cycloaddition $\left(k_{3}>>k_{4}\right)$ is the rate-limiting step. ${ }^{73}$ Insights into the rate trends from mechanistic studies help identify important elements of monomer design and, therefore, opportunities for controlled copolymerization.

Copolymerization Kinetics. In order to analyze the copolymerization kinetics of a macromonomer and a discrete comonomer, the Mayo-Lewis terminal model was adapted for G3catalyzed ROMP. ${ }^{38}$ The terminal model assumes that, for a mixture of two monomers $\mathrm{M}_{1}$ and $\mathrm{M}_{2}$, there are two propagating species $\left(\mathrm{M}_{1} *\right.$ and $\left.\mathrm{M}_{2}{ }^{*}\right)$ whose reactivities solely depend on the last-incorporated monomer. ${ }^{74}$ The copolymerization kinetics can be captured by four propagation reactions involving $\mathrm{M}_{1}$ * and $\mathrm{M}_{2}{ }^{*}$, each described by a unique rate constant $k$. Figure 6 shows the relevant reactions for a mixture of a discrete diluent $\left(\mathrm{M}_{2}\right)$ and a macromonomer $\left(\mathrm{M}_{1}\right)$ : (A) diluent self-propagation $\left(\mathrm{M}_{2}{ }^{*} \rightarrow \mathrm{M}_{2} *, k_{22}\right)$, (B) cross-propagation via addition of $\mathrm{M}_{1}$ to $\mathrm{M}_{2} *\left(\mathrm{M}_{2} * \rightarrow \mathrm{M}_{1} *, k_{21}\right)$, (C) macromonomer self-propagation $\left(\mathrm{M}_{1} * \rightarrow \mathrm{M}_{1} *, k_{11}\right)$, and (D) cross-propagation via addition of $\mathrm{M}_{2}$ to $\mathrm{M}_{1} *\left(\mathrm{M}_{1} * \rightarrow \mathrm{M}_{2} *, k_{12}\right)$. The conversion over time of all species can be described by a system of four ordinary differential equations. Non-linear least squares regression, described in a previous report, ${ }^{38}$ was used to fit the instantaneous monomer concentrations over the entire course of the copolymerization. Finding the best numerical solutions for the cross-propagation rates $k_{12}$ and $k_{21}$ enables determination of the reactivity ratios, $r_{1}$ $=k_{11} / k_{12}$ and $r_{2}=k_{22} / k_{21}$.

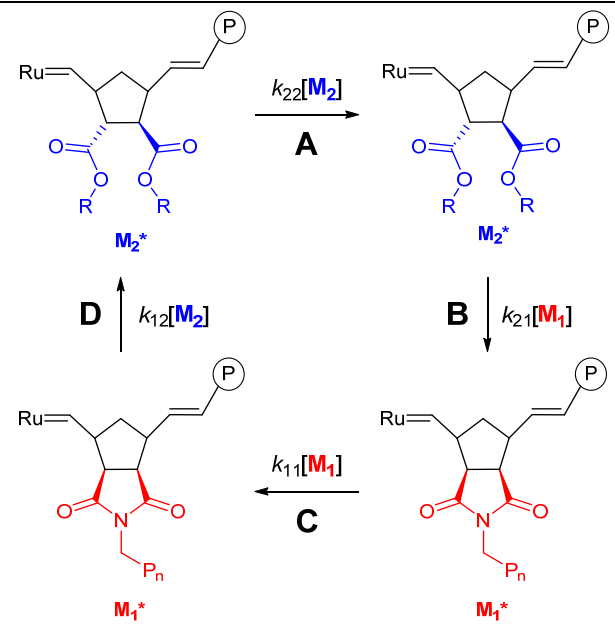

Figure 6. Propagation reactions for the copolymerization of a discrete diluent ( $\mathrm{M}_{2}, d x$-DE shown for example) and a macromonomer 
$\left(\mathrm{M}_{1}\right)$ according to a terminal model. $\mathrm{M}_{2} *$ and $\mathrm{M}_{1} *$ are the corresponding propagating alkylidene species. (A) Diluent self-propagation $\left(k_{22}\right)$, (B) cross-propagation $\left(k_{21}\right)$, (C) macromonomer selfpropagation $\left(k_{11}\right),(\mathrm{D})$ cross-propagation $\left(k_{12}\right)$.

The relative reactivity, captured by $r_{1}$ and $r_{2}$, determines the polymer sequence. $r_{1}$ and $r_{2}$ can be tuned by building on insights into homopolymerization rate trends. Monomer design ultimately enables architecture design: for a polymerizable macromonomer with any side chain chemistry, a discrete co-monomer can be selected among those in Figure 4 or otherwise designed to target desired backbone sequences. In turn, control over the backbone sequence directly controls side chain distribution. We will first discuss general trends and opportunities for copolymerization, then outline potential implications for polymer architectures by design.

In order to study the impact of monomer structure on the copolymerization kinetics, we selected 13 diluents and copolymerized each with the same $\omega$-norbornenyl macromonomer (PLA, $M_{\mathrm{n}}=3230 \mathrm{~g} \mathrm{~mol}^{-1}$ ) (Figure 7A). Figure 7B arranges these discrete co-monomers in order of increasing $k_{22}$. For all copolymerization experiments, the total backbone degree of polymerization $\left(N_{\mathrm{bb}}\right)$ and monomer feed ratio $(f)$ were fixed: given $x$ equivalents of the diluent and $y$ equivalents of PLA relative to 1 equivalent of $\mathbf{G 3}, N_{\mathrm{bb}}=x+y \approx 200$ and $f=x / y \approx 1$. The copolymerization conditions, including monomer and catalyst concentrations, were identical to those for the homopolymerization experiments described above: $\left[\mathrm{M}_{1}\right]_{0}=\left[\mathrm{M}_{2}\right]_{0}=50$ $\mathrm{mM},[\mathbf{G} 3]_{0}=0.5 \mathrm{mM}^{75}$ The kinetics were monitored in the same way as the homopolymerization kinetics, i.e., by quenching aliquots of the polymerization mixture. The instantaneous concentrations of the macromonomer and diluent were determined by integrating the olefin resonances in ${ }^{1} \mathrm{H}$ NMR spectra, and $k_{12}$ and $k_{21}$ were obtained by non-linear least squares regression. SEC data for all copolymers indicate low dispersities $(~ Ð$ $<1.1$ ) and similar molecular weights (Figure S10, Table S2).

Figure $7 \mathrm{C}$ shows the self-propagation rate constants $\left(k_{11}\right.$, $k_{22}$ ) and reactivity ratios $\left(r_{1}, r_{2}\right)$ for the copolymerization of PLA $\left(\mathrm{M}_{1}\right)$ with different diluents $\left(\mathrm{M}_{2}\right)$. (All data, including the cross-propagation rate constants $k_{12}$ and $k_{21}$, are compiled in Table S3.) $k_{11}$ is constant throughout the series $\left(=17.2 \mathrm{M}^{-1} \mathrm{~s}^{-1}\right)$ since $\mathrm{M}_{1}$ is the same in each co-monomer pair, while $k_{22}$ varies over a wide range due to anchor group and substituent effects (2d: $0.362 \mathrm{M}^{-1} \mathrm{~s}^{-1}$ to $5 \mathrm{a}: 82.4 \mathrm{M}^{-1} \mathrm{~s}^{-1}$ ). As $k_{22}$ increases, $r_{2}$ also increases. The magnitude of $r_{2}$ reflects the reactivity of the propagating alkylidene $\mathrm{M}_{2}{ }^{*}$ toward free $\mathrm{M}_{1}$ and $\mathrm{M}_{2}{ }^{76}$ In the case that $r_{2}<1$, for example when PLA is copolymerized with $d d$-DE or $d$-I diluents ( $\mathbf{2 d}$ to $\mathbf{2 a}, 0.4<r_{2}<0.9$ ), $\mathrm{M}_{2} *$ preferentially adds $\mathrm{M}_{1}$. In the opposite case $r_{2}>1$, for example when PLA is copolymerized with $d x$-DE, $x x$-DE, or $x$-I diluents (3d to $\left.\mathbf{5 a}, 1.2<r_{2}<3.1\right), \mathrm{M}_{2} *$ preferentially adds $\mathrm{M}_{2}$ instead. In other words, if a diluent is the terminal unit of the propagating species, the probability of incorporating either a macromonomer or another diluent reflects the difference between the homopolymerization rate constants: when $k_{22}<k_{11}, r_{2}<1$ and $\mathrm{M}_{2}$ * favors macromonomer addition; on the other hand, when $k_{22}>$ $k_{11}, r_{2}>1$ and $\mathrm{M}_{2}{ }^{*}$ favors diluent addition. ${ }^{77}$ Translating these trends to the copolymer sequence also requires examination of $r_{1}$, which reflects consumption of the other propagating species $\mathrm{M}_{1}{ }^{*}$. Figure $7 \mathrm{C}$ shows that, as $k_{22}$ increases, $r_{1}$ generally decreases, opposite the trend observed for $r_{2}$. These observations suggest that both $\mathrm{M}_{1} *$ and $\mathrm{M}_{2} *$ (1) favor incorporating $\mathrm{M}_{2}$ when $k_{22} \gtrsim k_{11}$ and (2) favor incorporating $\mathrm{M}_{1}$ when $k_{22}<k_{11}$. In other words, both cross-propagation terms $\left(k_{12}\right.$ and $\left.k_{21}\right)$ are functions of the incoming olefin (to first order) and appear relatively insensitive to the nature of the pendant chain.

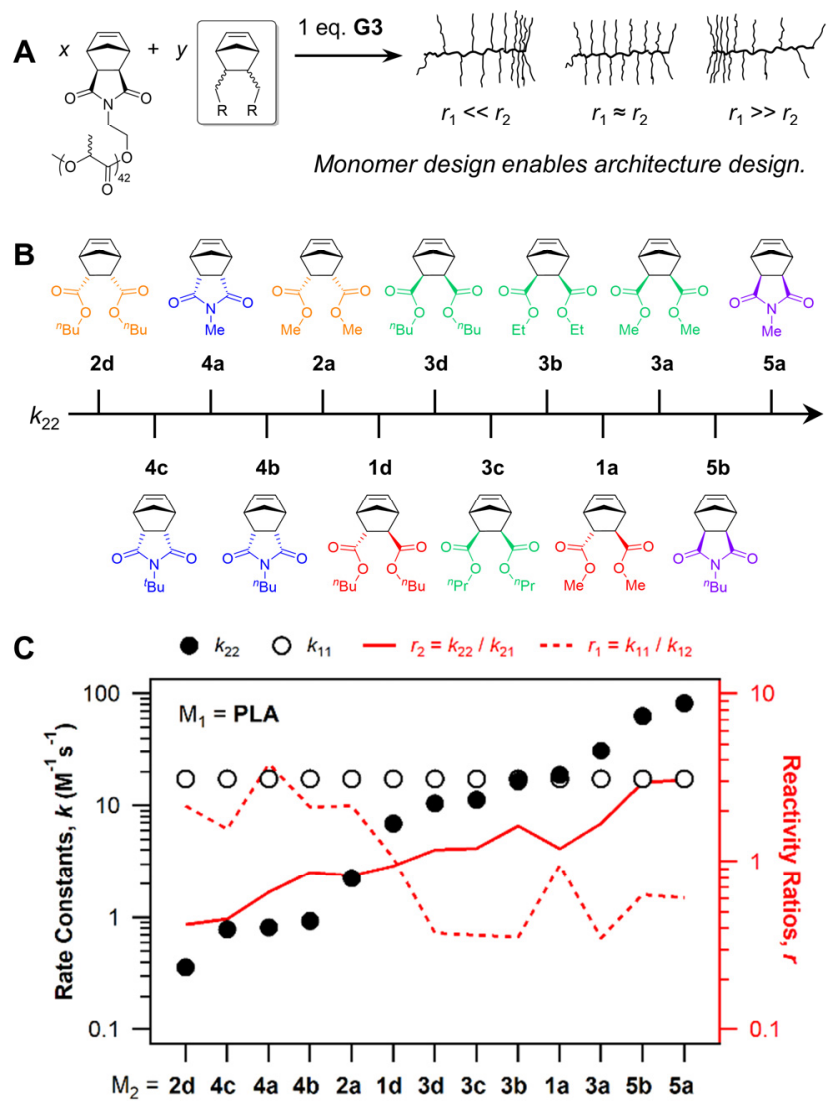

Figure 7. (A) Copolymerization scheme: the same macromonomer (PLA, $\mathrm{M}_{1}$ ) was copolymerized with 13 different diluents $\left(\mathrm{M}_{2}\right)$. The feed ratio $(x / y=1)$ and total backbone length $(x+y=200)$ were fixed. (B) $\mathrm{M}_{2}$ arranged in order of increasing $k_{22}$. (C) PLA/diluent copolymerization data. Left axis, black: self-propagation rate constants ( $k_{22}$ : filled circles, $k_{11}$ : open circles). Right axis, red: reactivity ratios ( $r_{2}$ : solid line, $r_{1}$ : dotted line).

We note that, while $r_{1}$ generally decreases with increasing $k_{22}$, the trend is not monotonic. These results highlight the additional complexity that copolymerization introduces. While informative, the difference between the homopolymerization rate constants $\left(k_{11}-k_{22}\right)$ is not a universal predictor for the values of $r_{1}$ and $r_{2}$ (nor therefore the copolymer sequence). For example, when PLA is copolymerized with a $x x$-DE diluent, $r_{2}$ varies but $r_{1}$ remains the same $(=0.36 \pm 0.02)$, regardless of whether $k_{22}<$ $k_{11}\left(\mathbf{3 d}, \mathbf{3 c}\right.$, and 3b) or $k_{22}>k_{11}$ (3a). Meanwhile, when PLA is copolymerized with the $d x$-DE analogue of $\mathbf{3 a}$ (i.e., 1a), the self-propagation rates are equal $\left(k_{22}=k_{11}\right)$ and both $r_{1}$ and $r_{2}$ are approximately equal to 1 . These observations suggest that the key interactions identified in our study of diluent homopolymerization rate trends do not fully capture the relative reactivity upon copolymerization. The individual second-order rate constants $\left(k_{11}, k_{12}, k_{21}, k_{22}\right)$ are affected by both (1) pyridine binding $\left(K_{\text {eq, } 2}\right)$ and $(2)$ chelation and olefin binding $\left(k_{3}\right)$. Both those 
terms are inherently dictated by the identities of the approaching olefin monomer and the propagating alkylidene. While elucidating the origin of copolymerization rate trends is outside the scope of this report, we note that the large disparity between the molecular weights of the PLA macromonomer and diluents (10to 20-fold) likely plays a significant role in the departure from simple chain-end control. Under the copolymerization conditions (rapid stirring in dilute solution), simple diffusion of free monomers to the catalyst active site is not expected to limit propagation. However, beyond the anchor group and substituent effects outlined for discrete diluents, the presence of polymeric side chains in proximity to the metal center should amplify steric congestion. Excluded volume interactions and solvent quality may further affect the steric and electronic environment around the propagating metal center.

Graft Polymer Architecture. Monitoring the copolymerization kinetics enables determination of the instantaneous composition and therefore the graft polymer architecture. Using the experimentally determined rate constants, the probability of incorporating either a diluent or a macromonomer at any point in the growing chain can be simulated. ${ }^{38}$ Figure 8 plots these probabilities as a function of the total conversion for several PLA/diluent pairs. If $r_{1}>r_{2}$, gradient sequences are obtained. The copolymers are rich in $\mathrm{M}_{1}$ at early conversions and rich in $\mathrm{M}_{2}$ at later conversions, producing tapered side chain distributions (e.g., PLA $+4 \mathbf{4 a}$, Figure 8A). If $r_{1} \approx r_{2} \approx 1$, the copolymer backbone sequence is approximately random and therefore the side chains are uniformly distributed (e.g. PLA + 1a, Figure 8B). Lastly, if $r_{1}<r_{2}$, the inverse-tapered graft polymers are obtained, which are rich in $\mathrm{M}_{2}$ at early conversions and rich in $\mathrm{M}_{1}$ at later conversions (e.g., PLA + 5a, Figure 8C).

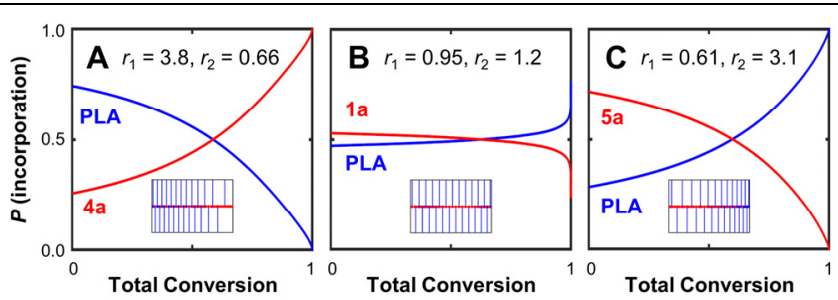

Figure 8. Simulated sequences and (inset) graft polymer architectures for the copolymerization of PLA with different diluents: (A) 4a, (B) 1a, or (C) 5a. For ease of visualization, the simulated structures show fully extended side chains and backbones.

The ROMP copolymerization strategy outlined herein provides a general approach to architecture design for any side chain chemistry. In principle, given any polymerizable macromonomer, a diluent can be designed to access any desired sequence. Although the magnitudes of $r_{1}$ and $r_{2}$ cannot presently be predicted de novo, insights into the relationships among $r_{1}$, $r_{2}$, and diluent structure should guide the selection of appropriate macromonomer/diluent pairs. In order to further illustrate these design principles, the copolymerization kinetics of various diluents with either a PDMS $\left(M_{\mathrm{n}}=1280 \mathrm{~g} \mathrm{~mol}^{-1}\right)$ or PS $\left(M_{\mathrm{n}}\right.$ $=3990 \mathrm{~g} \mathrm{~mol}^{-1}$ ) macromonomer were also studied. PDMS and PS polymerize faster $\left(k_{11}=21.6 \mathrm{M}^{-1} \mathrm{~s}^{-1}\right)$ and slower $\left(k_{11}=4.18\right.$ $\mathrm{M}^{-1} \mathrm{~s}^{-1}$ ) than PLA, respectively. The selected diluents all homopolymerize slower than PDMS $\left(k_{22}<k_{11}\right.$, with the exception of 3a) and faster than PS $\left(k_{22}>k_{11}\right)$. The self-propagation rate constants and reactivity ratios are provided in Figure 9. All values are compiled in Tables S4-S5, and SEC data are provided in Figures S11-S12 and Tables S6-S7.

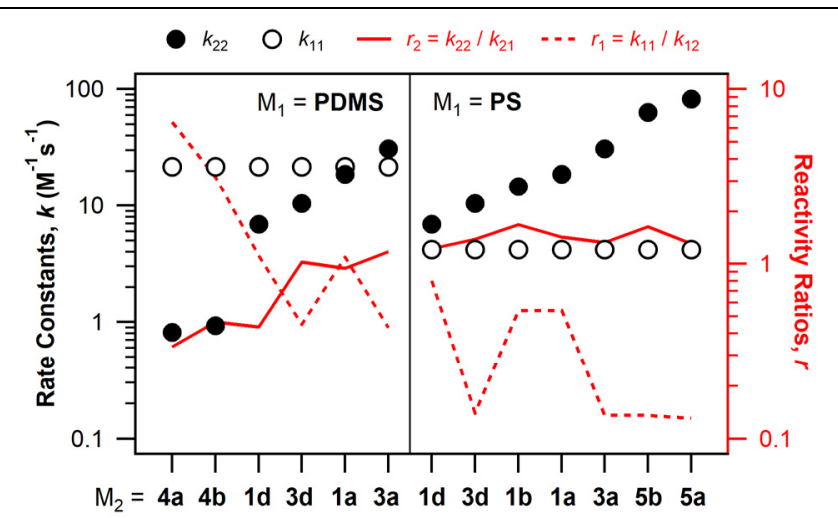

Figure 9. Data for the copolymerization of $M_{1}=$ PDMS (left) or PS (right) with different diluents. Left axis, black: self-propagation rate constants ( $k_{22}$ : filled circles, $k_{11}$ : open circles). Right axis, red: reactivity ratios ( $r_{2}$ : solid line, $r_{1}$ : dotted line).

Copolymerizations of PDMS with each of the selected diluents generally follow the same trends outlined for PLA/diluent copolymerizations. As $k_{22}$ increases while $k_{11}$ remains constant, $r_{2}$ increases and $r_{1}$ decreases. In other words, as $k_{22}$ increases, both $\mathrm{M}_{1} *$ and $\mathrm{M}_{2} *$ increasingly favor incorporating $\mathrm{M}_{2}$ instead of $\mathrm{M}_{1}$. The $x x$-DE diluents $(\mathbf{3 a}, \mathbf{3 d})$ are again outliers, leading to smaller values of $r_{1}$ than diluents with any other anchor group. As a result, at least for copolymerizations with PDMS or PLA macromonomers, the $x x$-DE anchor group inherently favors gradient sequences that are $\mathrm{M}_{2}$-rich at early conversions and $\mathrm{M}_{1}$-rich at later conversions. Copolymerizations of PS with any of the selected diluents reveal a similar kinetic preference for gradient sequences. Unlike copolymerizations with either PLA or PDMS, regardless of the relative magnitude of $k_{22}(2.7$ $\left.<k_{22}-k_{11}<78 \mathrm{M}^{-1} \mathrm{~s}^{-1}\right), r_{2}$ remains constant $(\approx 1)$. The constant magnitude of $r_{2}$ suggests that $\mathrm{M}_{2} *$ displays similar reactivity toward PS and any diluent. Meanwhile, since $\mathrm{M}_{1}$ * favors incorporating $\mathrm{M}_{2}\left(r_{1}<1\right)$, gradient sequences result.

The copolymerization kinetics for PLA, PDMS, and PS collectively illustrate how different diluents can be used to control the graft polymer architecture. The magnitudes of $r_{1}$ and $r_{2}$ determine the backbone sequence, which can be alternating $\left(r_{1}\right.$ $\left.\approx r_{2} \approx 0\right)$, blocky $\left(r_{1}, r_{2}>>1\right)$, gradient $\left(r_{1}>>r_{2}\right.$ or $\left.r_{1}<<r_{2}\right)$, or random $\left(r_{1} \approx r_{2} \approx 1\right) .{ }^{76}$ The backbone sequence in turn directly determines the side chain distribution (Figure 1). Figure 10 illustrates the wide range of distributions obtained by copolymerizing PLA, PDMS, or PS with selected diluents. The relative reactivities of the macromonomers and diluents are interpreted in terms of the quotient $r_{1} / r_{2}$, which reflects the kinetic preference for the chain end (either $\mathrm{M}_{1} *$ or $\mathrm{M}_{2} *$ ) to incorporate $\mathrm{M}_{1}$ over $\mathrm{M}_{2}$.

PLA/diluent copolymerizations obtain $r_{1} / r_{2}$ ranging from 0.20 (PLA + 5a) to 5.8 (PLA + 4a). Copolymerizing PDMS with $\mathbf{4 a}$, one of the slowest-polymerizing diluents studied herein, produces a remarkably large difference between $r_{1}$ and $r_{2}: r_{1} / r_{2}=19$. This large disparity in reactivity results in a highly gradient - potentially even blocky - distribution of side chains. Since $r_{1} \gg r_{2}$, the graft polymers are densely grafted (i.e., rich in $\mathrm{M}_{1}$ ) at early conversions and loosely grafted (i.e., rich in $\mathrm{M}_{2}$ ) at later conversions. Copolymerizing PS with $\mathbf{5 b}$, one of the 
fastest-polymerizing diluents introduced in this report, also affords a wide gap in reactivity: $r_{1} / r_{2}=0.084$. Compared to PDMS + 4a, the inverse-tapered sequence is obtained. The ability to invert the gradient direction may not affect the properties of homopolymers, but it is valuable in the design of block polymers and other multicomponent materials. In the final section, we will demonstrate the physical consequences of varying the sequence distribution in the context of block polymer self-assembly.

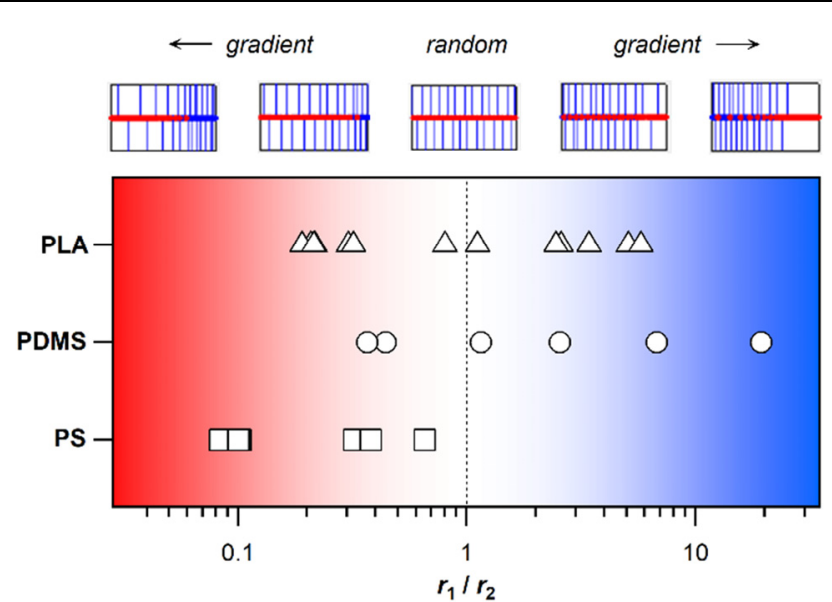

Figure 10. Reactivity ratio map. The copolymerization kinetics studied for PLA, PDMS, and PS are interpreted in terms of the quotient $r_{1} / r_{2}$, plotted on the X-axis. For ease of visualization, the simulated structures show fully extended side chains and backbones.

Physical Consequences. Grafting density and graft distribution are important parameters that govern polymer architectures and physical properties. Grafting-through ring-opening metathesis copolymerization has recently been exploited to study how grafting density affects the scaling of the block polymer lamellar period..$^{78}$ In the final section of this report, we will further demonstrate the utility of the ROMP method by describing the synthesis of $\mathrm{AB}$ diblock polymers with variable side chain distributions, then examine how differences in chain connectivity affect self-assembly.

Three different AB graft diblock polymers were synthesized by controlled ROMP. Simple substitutions of the discrete comonomers ensure that the block polymers differ only in the distribution of the grafts. All other aspects of the structure and chemistry are identical:

- All block polymers feature PDMS and PS side chains. The grafting-through approach guarantees that the side chain molecular weights are the same within each block (PDMS: $1280 \mathrm{~g} \mathrm{~mol}^{-1}$, PS: $3990 \mathrm{~g} \mathrm{~mol}^{-1}$ ).

- The grafting density in each block is $50 \%$.

- The backbone degree of polymerization in each block is the same. For the A block (PDMS + diluent), $N_{\mathrm{bb}, \mathrm{A}}=150$; for the B block (PS + diluent), $N_{\mathrm{bb}, \mathrm{B}}=50$.

- The above constraints enforce equal block volume fractions for all three block polymers: $f=0.50$.

The side chain distributions can be varied while fixing all of the preceding parameters by switching the identity of the diluents in each block. Figure 11A illustrates the resulting architec- tures with uniform (BP-1) or gradient (BP-2, BP-3) graft distributions. The backbones are drawn in the fully extended limit for ease of visualization, and the side chain conformations and cross-sectional radii are depicted as anticipated by existing theory. $5,44-46$

BP-1 was synthesized by first copolymerizing PDMS and endo,exo-norbornenyl dimethylester $(d x$-DMeE, 1a) in a $1: 1$ feed ratio. Since $r_{1}=1.1$ and $r_{2}=0.94$, the first block has an ideal random backbone sequence and therefore uniform side chain distribution. After complete consumption of PDMS and $d x$-DMeE, the chain ends were still living, and the second block (B) was added via a 1:1 mixture of PS and endo,exo-norbornenyl di- $n$-butylester $\left(d x-\mathrm{D}^{n} \mathrm{BuE}, \mathbf{1 d}\right)$. Since $r_{1}=0.80$ and $r_{2}$ $=1.2$, the side chain distribution in the second block is also effectively uniform. A graft polymer with a gradient side chain distribution (BP-2) was synthesized by keeping all conditions exactly the same but simply switching the diluents. The first block (A) was synthesized by copolymerizing PDMS with $d x$ $\mathrm{D}^{n} \mathrm{BuE}$ instead of $d x$-DMeE; since $r_{1}=1.1$ and $r_{2}=0.43$, the block is rich in the macromonomer at early conversions and rich in the diluent at late conversions. Addition of PS $+d x$-DMeE as the second block $\left(\mathrm{B} ; r_{1}=0.54, r_{2}=1.4\right)$ therefore produces a block polymer with low grafting density at the block-block junction and increasing grafting density moving toward the free chain ends. A third distinct graft block polymer (BP-3) was synthesized by keeping all conditions exactly the same as those for BP-2 but simply switching the order in which the blocks were added. By polymerizing block B (PS $+d x$-DMeE) first and block A (PDMS $\left.+d x-\mathrm{D}^{n} \mathrm{BuE}\right)$ second, the product features the inverse-tapered architecture compared to BP-2. Figure S13 provides the chemical structures of BP-1, -2, and -3. Analysis by SEC (Figure S14) and ${ }^{1} \mathrm{H}$ NMR (Figure S15) confirms that their overall molecular weights and chemical compositions are identical.

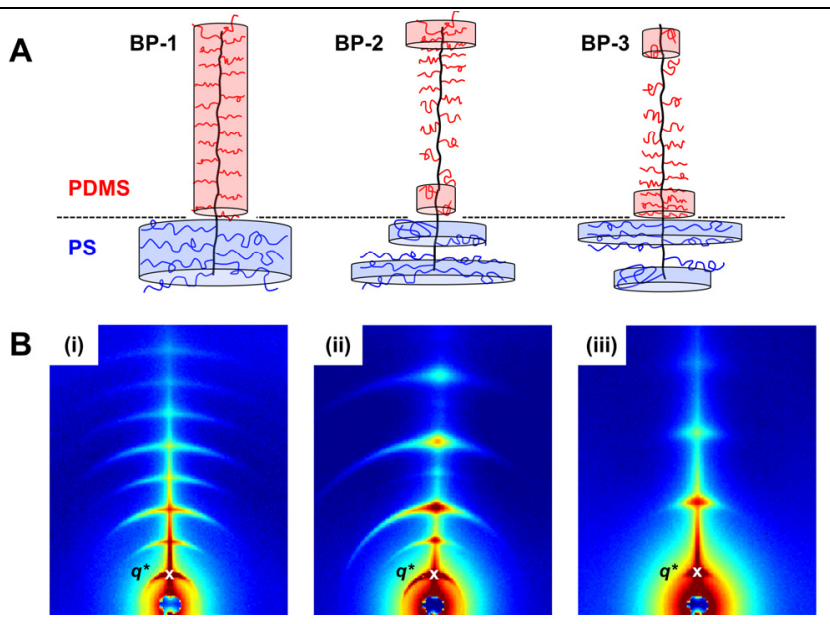

Figure 11. (A) Illustrations of three $A B$ graft diblock polymers, differing only in the side chain distribution: uniform (BP-1), gradient (BP-2), and inverse-gradient (BP-3). The horizontal dotted line indicates the junction between blocks. (B) SAXS patterns corresponding to the annealed block polymers: (i) BP-1, (ii) BP-2, (iii) BP-3. The white " $\mathrm{x}$ " indicates the first-order diffraction peak, $q^{*}$.

The three graft block polymers were annealed for 24 hours at $140{ }^{\circ} \mathrm{C}$ under vacuum and modest applied pressure. The resulting microphase-separated structures were characterized by 
synchrotron-source small-angle X-ray scattering (SAXS). Comparison of the SAXS patterns (Figure 11B) indicates that all three samples form long-range-ordered lamellar morphologies but also reveals two crucial differences. First, the lamellar periods $\left(d^{*}=2 \pi / q^{*}\right)$ differ. Equal values of $d^{*}$ are perhaps expected since the chemical compositions and backbone and side chain lengths are all identical; on the contrary, BP-1 exhibits $d^{*}$ $=51.0 \mathrm{~nm}$ (Figure 11B.i), while BP-2 (11B.ii) and BP-3 (11B.iii) exhibit $d^{*}=49.5$ and $46.5 \mathrm{~nm}$, respectively. Second, the relative thicknesses of the $\mathrm{A}$ and $\mathrm{B}$ domains $\left(d_{\mathrm{A}}\right.$ and $\left.d_{\mathrm{B}}\right)$ also differ. Compared to BP-1, BP-2 forms more symmetric lamellae, as evidenced by the weak intensities of the even-order diffraction peaks $\left(q_{2}, q_{4}, \ldots\right)$. The inverse-gradient $\mathbf{B P}-\mathbf{3}$ forms lamellae that are the most symmetric of all; in fact, the complete extinction of even-order peaks suggests that $d_{\mathrm{A}}$ and $d_{\mathrm{B}}$ are equal.

This symmetry is perhaps surprising: although the block volume fractions are equal $(f=0.50)$, the backbone lengths are highly asymmetric: $N_{\mathrm{bb}, \mathrm{A}}=3 N_{\mathrm{bb}, \mathrm{B}}$. The graft polymer backbones are clearly not fully extended as illustrated in Figure 11A. If the backbone were fully extended, $d_{\mathrm{A}}=3 d_{\mathrm{B}}$ is expected for all samples (Figure 12A). Every fourth diffraction peak $\left(q_{4}, q_{8}, \ldots\right)$ would be weak, which is inconsistent with the SAXS data. Instead, the SAXS data indicates that the backbones are flexible and that changing the side chain distribution affects the backbone conformation. Gradient distributions in which the grafting density is either lowest (BP-2) or highest (BP-3) at the blockblock junction enable more efficient packing than uniform distributions (BP-1). Closer packing balances the backbone asymmetry with the demands of equal block volumes, most likely via bending of the A (PDMS) block backbone (Figure 12B).

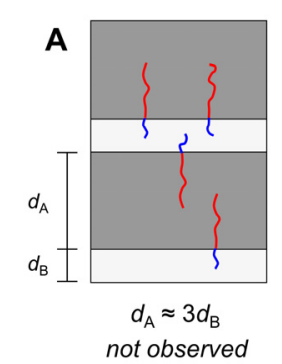

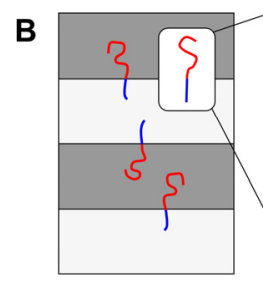

$d_{\mathrm{A}} \approx d_{\mathrm{B}}$

observed

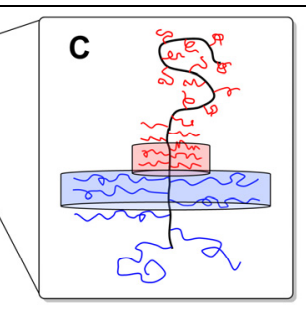

BP-3
Figure 12. Schematic illustration of the relationships between chain dimensions and the lamellar period. (A) $d_{\mathrm{A}} \approx 3 d_{\mathrm{B}}$ is expected if the backbones are fully stretched (since $N_{\mathrm{bb}, \mathrm{A}}=3 N_{\mathrm{bb}, \mathrm{B}}$ ), but it is consistent with SAXS data. (B) Instead, $d_{\mathrm{A}} \approx d_{\mathrm{B}}$ is observed. This requires bending of the A block backbone. (C) Illustration of BP-3 and revised chain conformations.

For all samples, the backbones should be strongly stretched at the domain interface as a consequence of segregation. In the case of BP-2, the chains should have the highest local backbone stiffness but also the greatest free volume at the free chain ends. Compared to the uniformly grafted BP-1, this may better accommodate high grafting density in the center of the domains. In the case of BP-3, since the backbones are already strongly stretched at the domain interfaces, the high grafting density may not significantly stretch the backbones further, resulting in the smallest $d^{*}$ among all three graft polymers. Low grafting density at the free chain ends should result in comparatively low backbone stiffness and therefore better accommodate bending in the A block (Figure 12C). Collectively, these results indicate that the side chain distribution affects chain stretching and packing. This result indicates that molecular "shape" is indeed an important design parameter, allowing materials to possess nonequilibrium density distributions.

\section{CONCLUSION}

Grafting-through ring-opening metathesis polymerization (ROMP) provides a versatile strategy for the design and synthesis of polymers with tailored side chain distributions. Controlled copolymerization of an $\omega$-norbornenyl macromonomer and a discrete norbornenyl diluent constructs graft architectures through the backbone; as a result, the backbone sequence directly dictates the side chain distribution. Since tuning the backbone sequence requires changing the relative reactivity of the co-monomers, we first investigated steric and electronic effects on the homopolymerization kinetics of 23 diluents. Varying the stereochemistry, anchor groups, and substituents varies the homopolymerization rate constants over two orders of magnitude $\left(0.36 \mathrm{M}^{-1} \mathrm{~s}^{-1} \leq k_{\text {homo }} \leq 82 \mathrm{M}^{-1} \mathrm{~s}^{-1}\right)$, reflecting a wide scope of monomer reactivity. These small-molecule monomers can be readily prepared and diversified, providing a convenient library for future development. In order to provide further guidance, we identified rate trends and studied their origins through complementary mechanistic studies. Density functional theory (DFT) calculations suggest that formation of a $\mathrm{Ru}-\mathrm{O}$ six-membered chelate (which sequesters the catalyst in an unproductive form) is significantly different for endo and exo isomers. Future studies will expand our understanding of the ROMP mechanism for both diluents and macromonomers. Other factors that could affect the ROMP kinetics, including for example solvent quality and additives, will also be explored.

Building on these results, we studied the copolymerization kinetics of selected diluents and a poly(D,L-lactide) (PLA), polydimethylsiloxane (PDMS), or polystyrene (PS) macromonomer. The co-monomer concentrations were monitored by ${ }^{1} \mathrm{H}$ NMR, and the cross-propagation rate constants were calculated by non-linear least squares regression based on the Mayo-Lewis terminal model. Trends involving the measured self-propagation rate constants and the calculated reactivity ratios $\left(r_{1}\right.$ and $\left.r_{2}\right)$ were identified. In general, for the 26 co-monomer pairs studied, the greater the difference between homopolymerization rates, the greater the gradient tendency $\left(r_{1} / r_{2}>>1\right.$ or $\left.r_{1} / r_{2}<<1\right)$. The backbone sequence - and therefore the polymer architecture - can be tailored simply by choosing the appropriate diluent among the library introduced herein or by designing an appropriate monomer. We note that, at present, de novo prediction of the reactivity ratios from the macromonomer and diluent chemical structures is not possible. However, we anticipate that the versatility of this design strategy, coupled with the broad functional group tolerance of ROMP and its living character, should enable the design and synthesis of graft polymers with almost any desired graft chemistry and graft distribution.

We further demonstrated the ease and versatility of this approach by synthesizing three $\mathrm{AB}$ graft diblock polymers that differ only in the distribution of side chains along the backbone. Analysis of the annealed, microphase-separated structures by small-angle X-ray scattering (SAXS) indicated that the graft block polymers all formed long-range-ordered lamellar structures. Differences in the lamellar periods and domain thicknesses reflect changes in the chain conformations. These results demonstrate the physical consequences of varying the side chain distribution. Ultimately, the design strategy outlined herein provides extensive customizability in terms of polymer 
structure and functionality, illuminating new opportunities for molecular and materials design.

\section{ASSOCIATED CONTENT}

\section{Supporting Information}

Monomer synthesis and characterization information, kinetic analysis, compiled rate constants and reactivity ratios. This material is available free of charge via the Internet at http://pubs.acs.org.

\section{AUTHOR INFORMATION}

\section{Corresponding Author}

*rhg@caltech.edu

\section{Author Contributions}

tA.B.C. and T.-P.L. contributed equally to this work.

\section{Notes}

The authors declare no competing financial interest.

\section{ACKNOWLEDGMENT}

This work was supported by the Department of Energy under award number DE-AR0000683 (ARPA-E Program) and by the National Science Foundation under award number CHE-1502616. A.B.C. thanks the U.S. Department of Defense for support through the NDSEG Fellowship. A.L.L.-M. thanks the Resnick Sustainability Institute at Caltech for fellowship support. The authors thank Prof J. C. Peters for access to computational resources. This research used resources of the Advanced Photon Source, a US Department of Energy Office of Science User Facility operated by Argonne National Laboratory under Contract DE-AC02-06CH11357.

\section{REFERENCES}

(1) Hadjichristidis, N.; Pitsikalis, M.; Pispas, S.; Iatrou, H. Chem. Rev. 2001, 101, 3747-3792.

(2) Polymeropoulos, G.; Zapsas, G.; Ntetsikas, K.; Bilalis, P.; Gnanou, Y.; Hadjichristidis, N. Macromolecules 2017, 50, 1253-1290.

(3) Bates, C. M.; Bates, F. S. Macromolecules 2016, 50, 3-22.

(4) Matyjaszewski, K.; Tsarevsky, N. V. Nature Chem. 2009, 1, 276-288.

(5) Kikuchi, M.; Nakano, R.; Jinbo, Y.; Saito, Y.; Ohno, S.; Togashi, D.; Enomoto, K.; Narumi, A.; Haba, O.; Kawaguchi, S. Macromolecules 2015, 48, 5878-5886.

(6) Liang, H.; Cao, Z.; Wang, Z.; Sheiko, S. S.; Dobrynin, A. V. Macromolecules 2017, 50, 3430-3437.

(7) Paturej, J.; Sheiko, S. S.; Panyukov, S.; Rubinstein, M. Sci. Adv. 2016, 2, e1601478.

(8) Rathgeber, S.; Pakula, T.; Wilk, A.; Matyjaszewski, K.; Beers, K. L. J. Chem. Phys. 2005, 122, 124904.

(9) Abbasi, M.; Faust, L.; Riazi, K.; Wilhelm, M. Macromolecules 2017, 50, 5964-5977.

(10) Dalsin, S. J.; Hillmyer, M. A.; Bates, F. S. Macromolecules 2015, 48, 4680-4691.

(11) Hu, M.; Xia, Y.; McKenna, G. B.; Kornfield, J. A.; Grubbs, R. H. Macromolecules 2011, 44, 6935-6943.

(12) Daniel, W. F. M.; Burdynska, J.; Vatankhah-Varnoosfaderani, M.; Matyjaszewski, K.; Paturej, J.; Rubinstein, M.; Dobrynin, A. V.; Sheiko, S. S. Nat. Mater. 2016, 15, 183-189.

(13) Mai, D. J.; Marciel, A. B.; Sing, C. E.; Schroeder, C. M. ACS Macro Lett. 2015, 4, 446-452.

(14) Kapnistos, M.; Kirkwood, K. M.; Ramirez, J.; Vlassopoulos, D.; Leal, L. G. J. Rheol. 2009, 53, 1133-1153.

(15) Read, D. J.; Auhl, D.; Das, C.; den Doelder, J.; Kapnistos, M.; Vittorias, I.; McLeish, T. C. B. Science 2011, 333, 1871-1874.
(16) Jeong, S. H.; Kim, J. M.; Baig, C. Macromolecules 2017, 50 , $4491-4500$

(17) Liberman-Martin, A. L.; Chu, C. K.; Grubbs, R. H. Macromol. Rapid Commun. 2017, 38, 1700058.

(18) Runge, M. B.; Bowden, N. B. J. Am. Chem. Soc. 2007, 129, 10551-10560.

(19) Sveinbjörnsson, B. R.; Weitekamp, R. A.; Miyake, G. M.; Xia Y.; Atwater, H. A.; Grubbs, R. H. Proc. Natl. Acad. Sci. U.S.A. 2012 109, 14332-14336.

(20) Qiu, L. Y.; Bae, Y. H. Biomaterials 2007, 28, 4132-4142.

(21) Johnson, J. A.; Lu, Y. Y.; Burts, A. O.; Lim, Y.-H.; Finn, M. G.; Koberstein, J. T.; Turro, N. J.; Tirrell, D. A.; Grubbs, R. H. J. Am. Chem. Soc. 2011, 133, 559-566.

(22) Bhattarai, N.; Ramay, H. R.; Gunn, J.; Matsen, F. A.; Zhang, M. J. Control. Release 2005, 103, 609-624.

(23) Bates, C. M.; Chang, A. B.; Momčilović, N.; Jones, S. C.; Grubbs, R. H. Macromolecules 2015, 48, 4967-4973.

(24) Bates, C. M.; Chang, A. B.; Schulze, M. W.; Momčilović, N.; Jones, S. C.; Grubbs, R. H. J. Polym. Sci., Part B: Polym. Phys. 2016 $54,292-300$

(25) Jiang, F.; Wang, Z.; Qiao, Y.; Wang, Z.; Tang, C. Macromolecules 2013, 46, 4772-4780.

(26) Zhang, J.; Schneiderman, D. K.; Li, T.; Hillmyer, M. A.; Bates, F. S. Macromolecules 2016, 49, 9108-9118.

(27) Ma, H.; Wang, Q.; Sang, W.; Han, L.; Liu, P.; Chen, J.; Li, Y.; Wang, Y. Macromol. Rapid Commun. 2015, 36, 726-732.

(28) Prudnikova, K.; Yucha, R. W.; Patel, P.; Kriete, A. S.; Han, L.; Penn, L. S.; Marcolongo, M. S. Biomacromolecules 2017, 18, 17131723

(29) Noel, A.; Borguet, Y. P.; Wooley, K. L. ACS Macro Lett. 2015, $4,645-650$.

(30) Wang, Q.; Ma, H.; Sang, W.; Han, L.; Liu, P.; Shen, H.; Huang, W.; Gong, X.; Yang, L.; Wang, Y.; Li, Y. Polym. Chem. 2016, 7, 3090 3099 .

(31) Grubbs, R. B.; Hawker, C. J.; Dao, J.; Fréchet, J. M. J. Angew Chem., Int. Ed. 1997, 36, 270-272.

(32) Shinoda, H.; Matyjaszewski, K. Macromolecules 2001, 34, $6243-6248$

(33) Börner, H. G.; Duran, D.; Matyjaszewski, K.; da Silva, M.; Sheiko, S. S. Macromolecules 2002, 35, 3387-3394.

(34) Lee, H.-i.; Matyjaszewski, K.; Yu, S.; Sheiko, S. S. Macromolecules 2005, 38, 8264-8271.

(35) Sutthasupa, S.; Shiotsuki, M.; Sanda, F. Polym. J. 2010, 42, 905-915.

(36) Bielawski, C. W.; Grubbs, R. H. Prog. Polym. Sci. 2007, 32, $1-29$.

(37) Leitgeb, A.; Wappel, J.; Slugovc, C. Polymer 2010, 51, $2927-$ 2946.

(38) Lin, T.-P.; Chang, A. B.; Chen, H.-Y.; Liberman-Martin, A. L.; Bates, C. M.; Voegtle, M. J.; Bauer, C. A.; Grubbs, R. H. J. Am. Chem. Soc. 2017, 139, 3896-3903.

(39) Zhang, B.; Gröhn, F.; Pedersen, J. S.; Fischer, K.; Schmidt, M. Macromolecules 2006, 39, 8440-8450.

(40) Sheiko, S. S.; Sumerlin, B. S.; Matyjaszewski, K. Prog. Polym. Sci. 2008, 33, 759-785.

(41) Zhang, M.; Müller, A. H. E. J. Polym. Sci., Part A: Polym. Chem. 2005, 43, 3461-3481.

(42) Lee, H.-i.; Pietrasik, J.; Sheiko, S. S.; Matyjaszewski, K. Prog. Polym. Sci. 2010, 35, 24-44.

(43) Peng, S.; Bhushan, B. RSC Advances 2012, 2, 8557-8578.

(44) Pesek, S. L.; Li, X.; Hammouda, B.; Hong, K.; Verduzco, R. Macromolecules 2013, 46, 6998-7005.

(45) Pesek, S. L.; Xiang, Q.; Hammouda, B.; Verduzco, R. J. Polym. Sci., Part B: Polym. Phys. 2017, 55, 104-111.

(46) Gerle, M.; Fischer, K.; Roos, S.; Müller, A. H. E.; Schmidt, M.; Sheiko, S. S.; Prokhorova, S.; Möller, M. Macromolecules 1999, 32, 2629-2637.

(47) Dettmer, C. M.; Gray, M. K.; Torkelson, J. M.; Nguyen, S. T. Macromolecules 2004, 37, 5504-5512. 
(48) Matyjaszewski, K.; Ziegler, M. J.; Arehart, S. V.; Greszta, D.; Pakula, T. J. Phys. Org. Chem. 2000, 13, 775-786.

(49) Sun, X.; Luo, Y.; Wang, R.; Li, B. G.; Zhu, S. AIChE J. 2008, 54, 1073-1087.

(50) Wang, R.; Luo, Y.; Li, B.-G.; Zhu, S. AIChE J. 2007, 53, 174186.

(51) Radzinski, S. C.; Foster, J. C.; Scannelli, S. J.; Weaver, J. R.; Arrington, K. J.; Matson, J. B. ACS Macro Lett. 2017, 6, 1175-1179.

(52) Grubbs, R. H.; Khosravi, E.: Handbook of Metathesis: Polymer Synthesis; Wiley, 2015.

(53) Moatsou, D.; Hansell, C. F.; O'Reilly, R. K. Chem. Sci. 2014, $5,2246-2250$.

(54) Slugovc, C.; Demel, S.; Riegler, S.; Hobisch, J.; Stelzer, F. Macromol. Rapid Commun. 2004, 25, 475-480.

(55) Radzinski, S. C.; Foster, J. C.; Chapleski, R. C.; Troya, D.; Matson, J. B. J. Am. Chem. Soc. 2016, 138, 6998-7004.

(56) Rosso, V. W.; Lust, D. A.; Bernot, P. J.; Grosso, J. A.; Modi, S. P.; Rusowicz, A.; Sedergran, T. C.; Simpson, J. H.; Srivastava, S. K.; Humora, M. J.; Anderson, N. G. Org. Process Res. Dev. 1997, 1, $311-314$.

(57) Xia, Y.; Kornfield, J. A.; Grubbs, R. H. Macromolecules 2009, 42, 3761-3766

(58) Miyake, G. M.; Weitekamp, R. A.; Piunova, V. A.; Grubbs, R. H. J. Am. Chem. Soc. 2012, 134, 14249-14254.

(59) Radzinski, S. C.; Foster, J. C.; Matson, J. B. Polym. Chem. 2015, 6, 5643-5652.

(60) Wolfe, P. S.; Wagener, K. B. Macromolecules 1999, 32, 79617967.

(61) Rule, J. D.; Moore, J. S. Macromolecules 2002, 35, 7878-7882.

(62) Pollino, J. M.; Stubbs, L. P.; Weck, M. Macromolecules 2003, $36,2230-2234$.

(63) Seehof, N.; Grutke, S.; Risse, W. Macromolecules 1993, 26, 695-700.

(64) Liu, P.; Taylor, B. L. H.; Garcia-Lopez, J.; Houk, K. N.: Computational Studies of Ruthenium-Catalyzed Olefin Metathesis. In Handbook of Metathesis; Wiley-VCH Verlag GmbH \& Co. KGaA, 2015; pp 199-252.

(65) Sanford, M. S.; Love, J. A.; Grubbs, R. H. J. Am. Chem. Soc. 2001, 123, 6543-6554.

(66) Adlhart, C.; Chen, P. J. Am. Chem. Soc. 2004, 126, 3496-3510.

(67) Vyboishchikov, S. F.; Bühl, M.; Thiel, W. Chem. Eur. J. 2002, 8, 3962-3975.

(68) Walsh, D. J.; Lau, S. H.; Hyatt, M. G.; Guironnet, D. J. Am. Chem. Soc. 2017, 139, 13644-13647.

(69) See SI for the full derivation. We could not exclude the possibility that cycloaddition is the rate-limiting step, which would result in a more complicated rate expression.

(70) Further discussion of the ROMP mechanism can be found in the SI. We note that, at present, we cannot conclusively rule out the stepwise or concerted associative/dissociative pathway.

(71) Fürstner, A.; Thiel, O. R.; Lehmann, C. W. Organometallics 2002, 21, 331-335.

(72) Benitez, D.; Tkatchouk, E.; Goddard, W. A. Organometallics 2009, 28, 2643-2645.

(73) In-depth DFT investigation of the ROMP mechanism, including calculation of transition-state structures and identification of the rate-limiting step, will be the subject of future work.

(74) Mayo, F. R.; Lewis, F. M. J. Am. Chem. Soc. 1944, 66, 1594 1601.

(75) In order to account for pyridine binding, it is critical to use the same $[\mathbf{G 3}]_{0}$ concentration in both homo- and copolymerization reactions. Further details can be found in the preceding section and SI.

(76) Odian, G.: Principles of Polymerization; 4th ed.; Wiley-Interscience: Hoboken, New Jersey, 2004.

(77) Meijs, G. F.; Rizzardo, E. J. Macromol. Sci., Polym. Rev. 1990, 30, 305-377.

(78) Lin, T.-P.; Chang, A. B.; Luo, S.-X.; Chen, H.-Y.; Lee, B.; Grubbs, R. H. ACS Nano 2017, Article ASAP, DOI: 10.1021/acsnano.7b06664. 


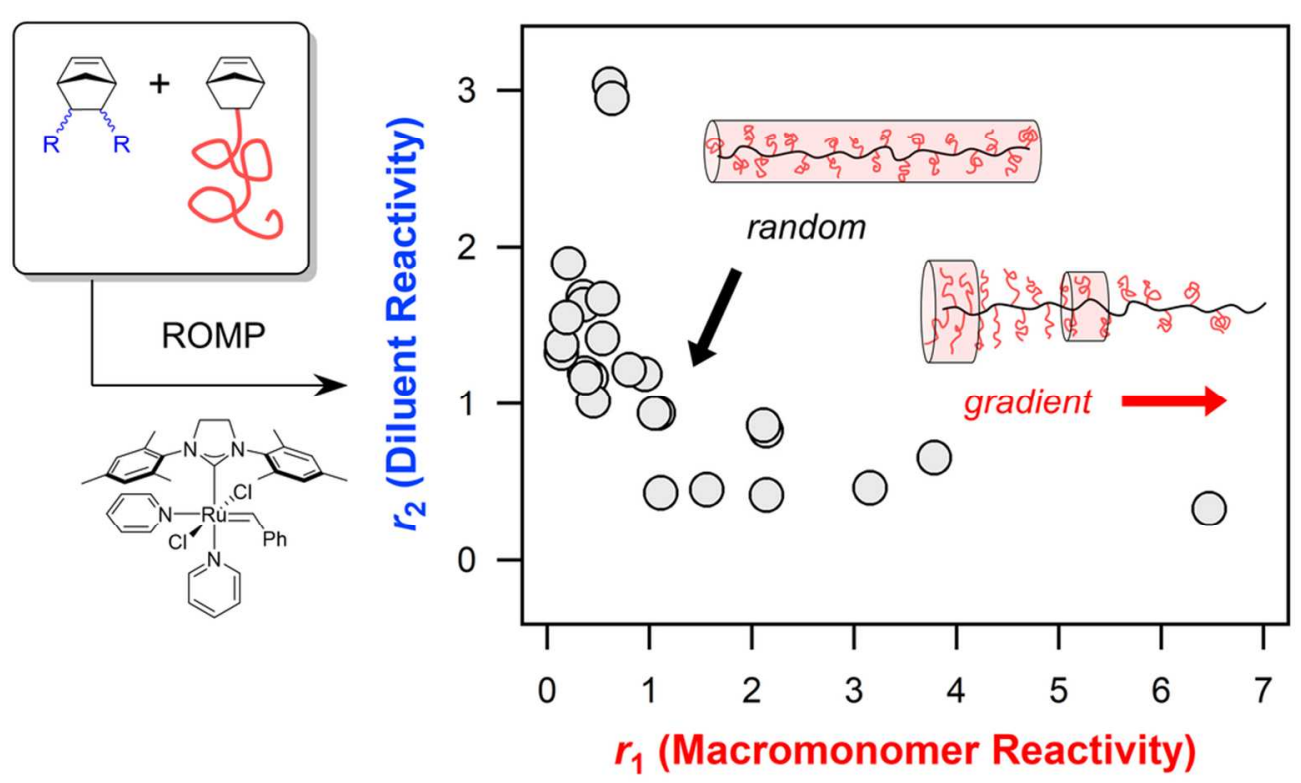

$46 \times 27 \mathrm{~mm}(600 \times 600$ DPI $)$ 
Figure 1. Grafting-through ROMP of a small-molecule diluent (white) and a macromonomer (black). Since the side chains (red) are connected to certain backbone units, control over the backbone sequence directly determines the side chain distribution: (A) uniform, (B) gradient, etc. The anticipated average crosssectional radius of gyration $\left(R_{\mathrm{c}}\right)$ is indicated. For ease of visualization, chains are illustrated in the limit of fully extended backbones.

$87 \times 90 \mathrm{~mm}(600 \times 600 \mathrm{DPI})$ 
Chart 1. Monomer design for ring-opening metathesis copolymerization.

\section{$45 \times 13 \mathrm{~mm}(600 \times 600$ DPI $)$}


Figure 2. Homopolymerization rate constants $\left(k_{\text {homo }}\right)$ for substituted endo,exo-norbornenyl diester monomers (left to right: $\mathbf{1 a - j}) . k_{\text {homo }}$ decreases with increasing steric bulk ( $R=M e$ to $\left.{ }^{t} \mathrm{Bu}, \mathbf{1} \mathbf{a}-\mathbf{f}\right)$. $k_{\text {homo }}$ does not change significantly with electronic changes via fluorination (19) or para-substitution of a phenyl ring $(\mathbf{1 h} \mathbf{- j})$.

\section{$41 \times 27 \mathrm{~mm}(300 \times 300 \mathrm{DPI})$}


Figure 3. (A) Homopolymerization rate constants ( $k_{\text {homo }}$ ) for monomers with exo,exo-diester ( $x x$, green), endo,exo-diester ( $d x$, red), and endo,endo-diester ( $d d$, yellow) anchor groups. Comparison of $k_{\text {homo }}$ for monomers with $\mathrm{R}=\mathrm{Me}$, $\mathrm{Et},{ }^{n} \mathrm{Pr}$, and ${ }^{n} \mathrm{Bu}$ supports the steric influences of stereochemistry and substituent size. (B) $k_{\text {homo }}$ for $\mathrm{Me}$ - and ${ }^{n} \mathrm{Bu}$-substituted monomers with each of the five anchor groups; endo-imide ( $d-I$, blue) and exo-imide ( $x$-I, purple).

\section{$46 \times 26 \mathrm{~mm}(300 \times 300 \mathrm{DPI})$}


Figure 4. Plot of $k_{\text {homo }}$ values for all monomers studied herein. The monomers are sorted according to their anchor groups: left to right: endo,exo-diester (red, $\mathbf{1} \mathbf{a}-\mathbf{j}$ ), endo,endo-diester (yellow, 2a-d), exo,exodiester (green, 3a-d), endo-imide (blue, $\mathbf{4 a - c}$ ), and exo-imide (purple, 5a-c and macromonomers). $k_{\text {homo }}$ values for methyl-substituted monomers are provided for comparison.

$$
74 \times 31 \mathrm{~mm}(600 \times 600 \mathrm{DPI})
$$



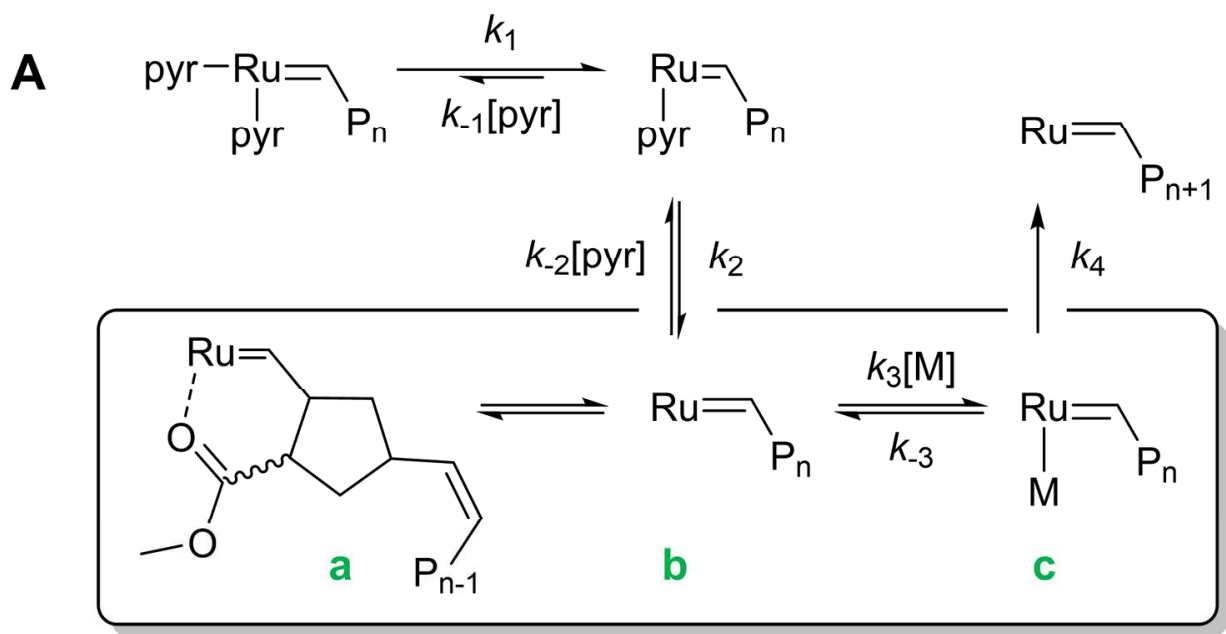

Figure 5. (A) Proposed dissociative ROMP pathway for G3. (B) DFT-calculated free energy diagram corresponding to one ROMP cycle for endo- (2a, blue) and exo-substituted (3a, red) norbornenyl monomers. The following intermediates were calculated: (a) six-membered Ru-O chelate, (b) 14-electron vacant species, (c) olefin adduct, and (d) metallacyclobutane.

$$
92 \times 102 \mathrm{~mm}(600 \times 600 \mathrm{DPI})
$$




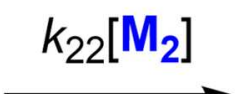

A<smiles>[R]OC(=O)/C(=C/[C@@H]1CC(C=[R1]=C)C[C@H]1/C=C/c1ccccc1)O[R]</smiles>

$M_{2}$ *<smiles>CC(C)C</smiles><smiles>O=C1[C@H](CN2C(=O)N(CP)C2=O)C[C@H]2C=[R1]=C[C@H](/C=C/c3ccccc3)[C@@H]12</smiles>

\section{$k_{11}\left[\mathrm{M}_{1}\right]$}

C
B $\downarrow k_{21}\left[\mathrm{M}_{1}\right]$<smiles>O=C1[C@H](CN2CN(CP)C2=O)C[C@H]2C=[R1]=C[C@H](/C=C/c3ccccc3)[C@@H]12</smiles>

$M_{1}$ *

Figure 6. Propagation reactions for the copolymerization of a discrete diluent $\left(M_{2}, d x\right.$-DE shown for example) and a macromonomer $\left(\mathrm{M}_{1}\right)$ according to a terminal model. $\mathrm{M}_{2} *$ and $\mathrm{M}_{1}$ * are the corresponding propagating alkylidene species. (A) Diluent self-propagation $\left(k_{22}\right),(\mathrm{B})$ cross-propagation $\left(k_{21}\right),(\mathrm{C})$ macromonomer self-propagation $\left(k_{11}\right),(D)$ cross-propagation $\left(k_{12}\right)$.

$63 \times 65 \mathrm{~mm}(600 \times 600 \mathrm{DPI})$ 


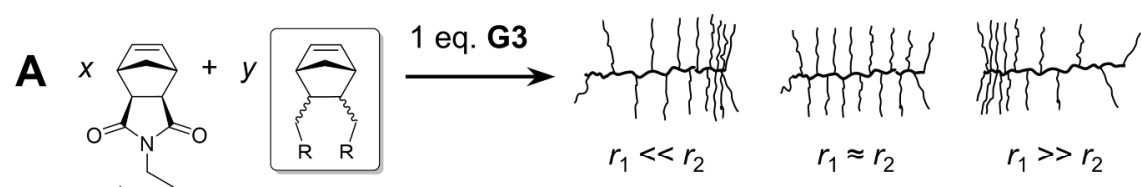

$y_{0} \prod_{0}^{\gamma_{42}^{0}} \quad$ Monomer design enables architecture design.
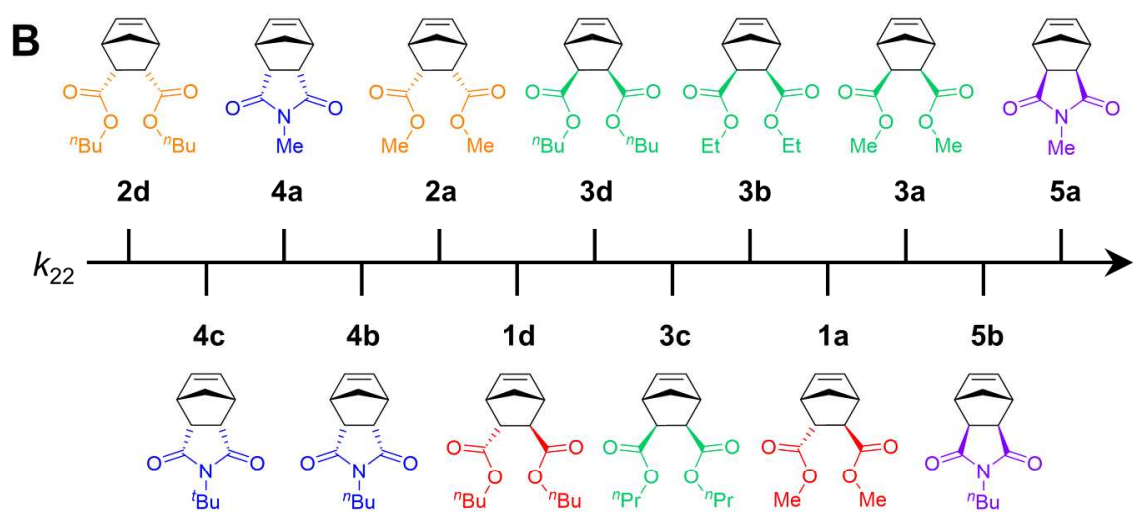

C $\quad k_{22} \bigcirc k_{11}-r_{2}=k_{22} / k_{21} \cdots r_{1}=k_{11} / k_{12}$

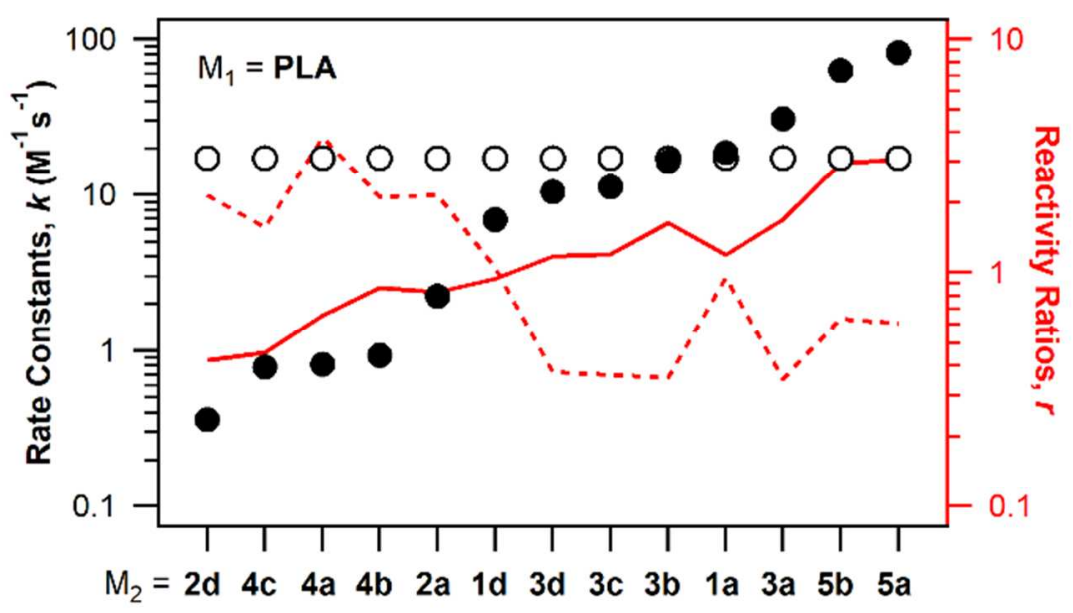

Figure 7. (A) Copolymerization scheme: the same macromonomer (PLA, $M_{1}$ ) was copolymerized with 13 different diluents $\left(M_{2}\right)$. The feed ratio $(x / y=1)$ and total backbone length $(x+y=200)$ were fixed. $(B) M_{2}$ arranged in order of increasing $k_{22}$. (C) PLA/diluent copolymerization data. Left axis, black: self-propagation rate constants ( $k_{22}$ : filled circles, $k_{11}$ : open circles). Right axis, red: reactivity ratios $\left(r_{2}\right.$ : solid line, $r_{1}$ : dotted line).

$114 \times 154 \mathrm{~mm}(600 \times 600 \mathrm{DPI})$ 

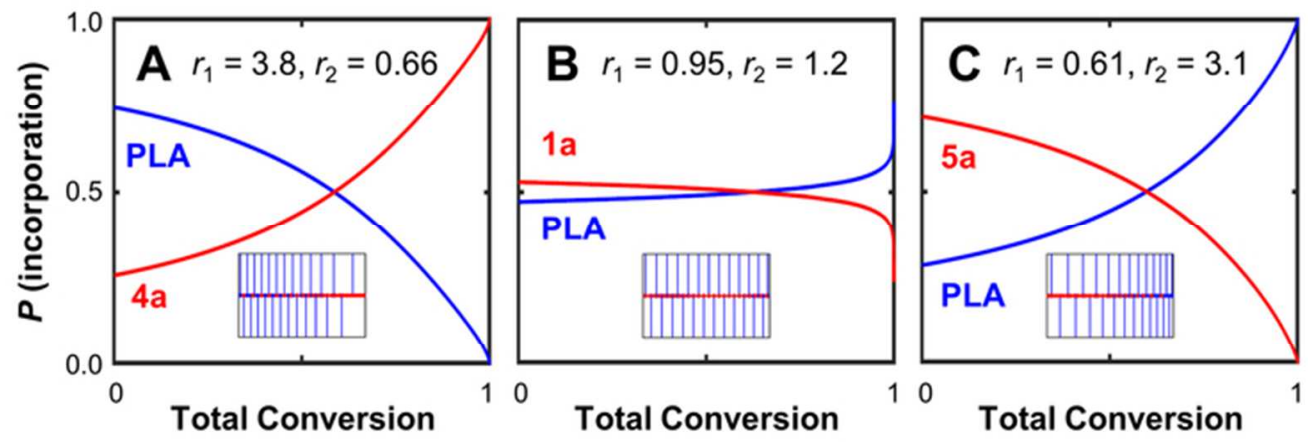

Figure 8. Simulated sequences and (inset) graft polymer architectures for the copolymerization of PLA with different diluents: (A) 4a, (B) 1a, or (C) 5a. For ease of visualization, the simulated structures show fully extended side chains and backbones.

$30 \times 11 \mathrm{~mm}(600 \times 600$ DPI $)$ 
Figure 9. Data for the copolymerization of $M_{1}=$ PDMS (left) or PS (right) with different diluents. Left axis, black: self-propagation rate constants ( $k_{22}$ : filled circles, $k_{11}$ : open circles). Right axis, red: reactivity ratios ( $r_{2}$ : solid line, $r_{1}$ : dotted line).

\section{$53 \times 35 \mathrm{~mm}(300 \times 300$ DPI $)$}


Figure 10. Reactivity ratio map. The copolymerization kinetics studied for PLA, PDMS, and PS are interpreted in terms of the quotient $r_{1} / r_{2}$, plotted on the $\mathrm{x}$-axis. For ease of visualization, the simulated structures show fully extended side chains and backbones.

$60 \times 43 \mathrm{~mm}(600 \times 600 \mathrm{DPI})$ 


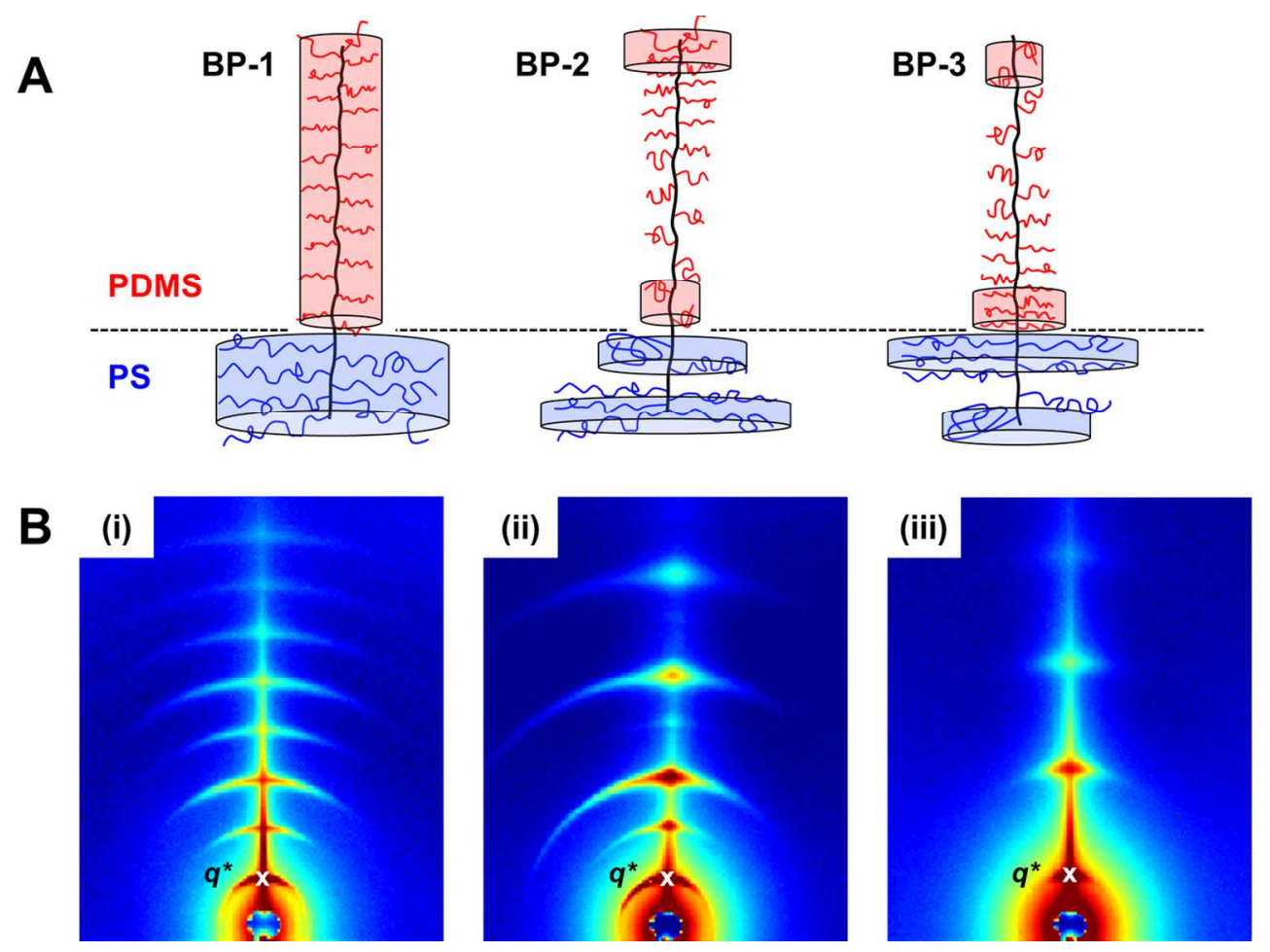

Figure 11. (A) Illustrations of three $A B$ graft diblock polymers, differing only in the side chain distribution: uniform (BP-1), gradient (BP-2), and inverse-gradient (BP-3). The horizontal dotted line indicates the junction between blocks. (B) SAXS patterns corresponding to the annealed block polymers: (i) BP-1, (ii) BP-2, (iii) BP-3. The white " $x$ " indicates the first-order diffraction peak, $q^{*}$.

$$
61 \times 44 \mathrm{~mm}(600 \times 600 \text { DPI })
$$


1

2

3

4

5

6

7

8

9

10

11

12

13

14

15

16

17

18

19

20

21

22

23

24

25

26

27

28

29

30

31

32

33

34

35

36

37

38

39

40

41

42

43

44

45

46

47

48

49

50

51

52

53

54

55

56

57

58

59

60

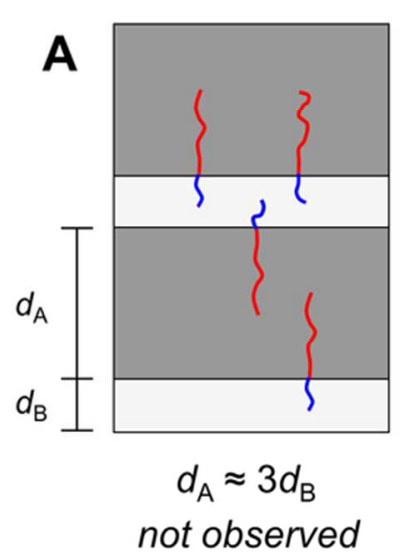

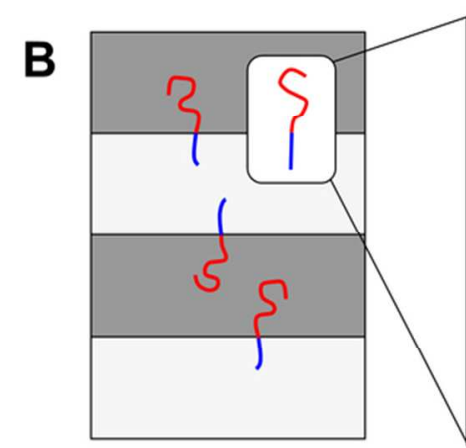

$d_{\mathrm{A}} \approx d_{\mathrm{B}}$

observed

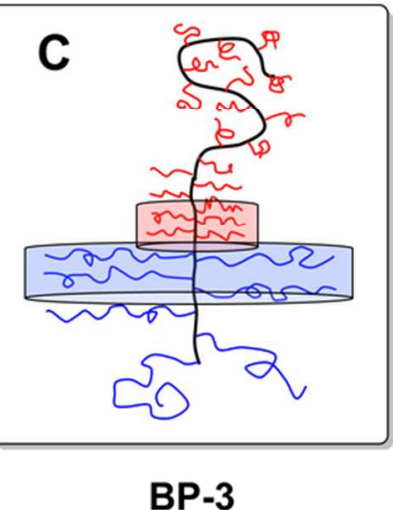

BP-3

Figure 12. Schematic illustration of the relationships between chain dimensions and the lamellar period. (A) $d_{\mathrm{A}} \approx 3 d_{\mathrm{B}}$ is expected if the backbones are fully stretched (since $N_{\mathrm{bb}, \mathrm{A}}=3 N_{\mathrm{bb}, \mathrm{B}}$ ), but it is consistent with SAXS data. (B) Instead, $d_{\mathrm{A}} \approx d_{\mathrm{B}}$ is observed. This requires bending of the A block backbone. (C) Illustration of BP3 and revised chain conformations.

$37 \times 16 \mathrm{~mm}(600 \times 600 \mathrm{DPI})$ 